\title{
Application and utilization of marker assisted selection for biotic stress resistance in hybrid rice (Oryza sativa L.)
}

\author{
Jae-Young Song $\cdot$ Sothea Ouk $\cdot$ Franz Marielle Nogoy $\cdot$ Marjohn C. Niño $\cdot$ Soon Wook Kwon $\cdot$ Woongoo Ha \\ Kwon-Kyoo Kang • Yong-Gu Cho
}

Received: 13 September 2016 / Revised: 13 September 2016 / Accepted: 21 September 2016

(c) Korean Society for Plant Biotechnology

\begin{abstract}
Development of disease resistant plant is one of the important objectives in rice breeding programs because biotic stresses can adversely affect rice growth and yield losses. This study was conducted to identify lines with multiple-resistance genes to biotic stress among 173 hybrid rice breeding lines and germplasms using DNA-based markers. Our results showed that one hybrid rice line [IR98161-21-1-k1-3 (IR86409-3-1-1-1-1-1/IRBB66)] possessed 5 bacterial blight resistance genes (Xa4, xa5, Xa7, Xa13 and Xa21) while two hybrid rice lines [IR98161-2-1-1-k1-2 (IR864093-1-1-1-1-1/IRBB66) and 7292s (IR75589-31-27-8-33S(S1)/ IR102758B)] possessed 3 bacterial blight resistance genes (Xa4, Xa7 and Xa21, and Xa3, Xa4 and Xa5). Molecular survey on rice blast disease revealed that most of these lines had two different resistant genes. Only 11 lines possessed $P i b, P i-5$, and Pi-ta. In addition, we further surveyed the distribution of insect resistant genes, such as $B p h 1, B p h 18(t)$, and Wbph. Three hybrid breeding lines [IR98161-2-1-1-k1-3 (IR86409-3-1-1-1-1-1/IRBB66), IR98161-2-1-1-k1-2 (IR864093-1-1-1-1-1/IRBB66), and 7292s (IR75589-31-27-8-33S(S1) /IR102758B)] contained all three resistance genes. Finally, we obtained four hybrid rice breeding lines and germplasms [IR98161-2-1-1-k1-2 (IR86409-3-1-1-1-1-1/IRBB66), Damm-
\end{abstract}

J.-Y. Song $\cdot$ S. Ouk $\cdot$ F. M. Nogoy $\cdot$ M. C. Niño $\cdot$ Y.-G. Cho (凹) Department of Crop Science, Chungbuk National University, Cheongju 28644, Korea

e-mail: ygcho@cbnu.ac.kr

S. W. Kwon

Department of Plant Bioscience, Pusan National University, Busan 50463, Korea

W. G. Ha

National Institute of Crop Science, Suwon 16429, Korea

K.-K. Kang

Department of Horticultural Life Science, Hankyong National University, Anseong 17579, Korea
Noeub Khmau, 7290s, and 7292s (IR75589-31-27-8-33S(S1)/ IR102758B)] possessing six-gene combination. They are expected to provide higher level of multiple resistance to biotic stress. This study is important for genotyping hybrid rice with resistance to diverse diseases and pests. Results obtained in this study suggest that identification of pyramided resistance genes is very important for screening hybrid rice breeding lines and germplasms accurately for disease and pest resistance. We will expand their cultivation safely through bioassays against diseases, pests, and disaster in its main export countries.

Keywords Hybrid, Rice, MAS, MAB, biotic stress, resistance

\section{Introduction}

Rice (Oryza sativa L.) is one of the most important and essential source of food crops for many people in the world. Maintaining stable rice production is extremely important to feed the constantly growing human population (Maclean et al. 2002; Sasaki and Burr 2000) in this ever changing climate. Improvement of disease resistance is an important objective in rice breeding programs because rice is exposed to various pests and several diseases including bacterial leaf blight (BB), rice blast (BL), sheath blight (ShB), tungro, and brown planthopper (BPH). Among diseases, bacterial leaf blight caused by Xanthomonas oryzae pv. oryzae (Xoo) is the most destructive bacterial disease of rice that limits rice yield in Asia (Mew 1987) and most of the rice growing countries. Rice blast disease caused by the ascomycete fungus, Magnaporthe oryzae (Couch and Kohn 2002), is also one of the leading causes of great yield loss of rice worldwide and is the most devastating fungal disease on cultivated rice as well as other species of the Poaceae (Zeigler et al. 1994; Talbot and Foster 2001; Talbot 2003; Niño et al. 2015). Rice tungro disease (RTD) is caused by two viruses, Rice tungro spherical virus 
(RTSV) and Rice tungro bacilliform virus (RTBV), and is one of the most serious diseases of rice in South and Southeast Asia (Lee et al. 2010). Rice damaged by RTD show symptoms, such as small growth and yellow-orange discoloration of leaves (Hibino 1983). Among the rice-feeding insects, Nilaparvata lugens, the rice brown planthopper (BPH) is the most damaging pest (Jiang et al. 2012). In addition, a rice phloem sap-sucking insect, whitebacked planthopper (WBPH) (Sogatella furcifera Horvath), can cause serious reductions in plant height, number of productive tillers, filled grains, and yield (Yamasaki et al. 2003).

Breeding for resistant varieties is the most effective control approach to prevent rice production losses as well as reduce pesticides usage. However, development of rice resistant cultivars by conventional breeding without checking the incorporation of resistant genes may lead to the breakdown of the disease resistance after new resistant cultivar is released, due to complexity of genetic control with complementary or additive effects as well as their environment interactions (Yaegashi 1994; Han et al. 2001). Therefore, it is necessary to develop durable resistance cultivars by incorporating several resistant genes against highly variable pathogen or pests (Bonman et al. 1986; Hittalmani et al. 2000) using markerassisted selection (MAS). Molecular marker techniques such as MAS may provide new ways for identifying and pyramiding valuable genes to enhance the disease resistance and overcome the breakdown of resistance that frequently occurs in rice breeding programs (Song et al. 2014; Ghulam et al. 2013). Conventional breeding approaches are difficult due to dominance and epistatic effects of genes governing disease resistance by gene pyramiding (Joseph et al. 2004; Rajpurohit et al. 2011). However, DNA-based genetic markers identified in accordance with the phenotypic traits or closed linked to each of the resistance genes are recently expected to play an important role in marker-associated breeding (MAB) for assessment of stress-tolerance and disease-resistance in hybrid breeding plants (Nogoy et al. 2016). According to Wang et al. (2005), developing super hybrid rice depends largely on the genetic resources of the parental lines and the conventional breeding technology. However, improving rice varieties based on this breeding technology is complicated, cumbersome and timeconsuming. Uncovering the molecular genetic control of rice heterosis would further improve hybrid rice technology.

To develop rice varieties that can withstand the current insect pest and disease problem in the rice growing regions, we initiate to establish rice breeding programs based on conventional breeding and advanced molecular breeding techniques.

\section{Materials and methods}

\section{Plant materials}

We used a rice panel comprised of 173 hybrid rice breeding lines and germplasms (Table 1) and control varieties (Table 2), which can be compared by size and presence/absence of amplicon between resistant and susceptible lines.

\section{DNA extraction}

Total genomic DNA was extracted from fresh leaves of two-week-old rice seedlings using modified Cetyl Trimethyl Ammonium Bromide (CTAB) method as previously described by Kump and Javornik (1996). DNA concentration was quantified using a spectrophotometer (NanoDrop One, Thermo Scientific). The DNA solution was then diluted to a working concentration with distilled water and stored at $-20^{\circ} \mathrm{C}$ until use.

\section{Genotyping}

Polymerase chain reaction (PCR) was performed using resistant and susceptible gene-specific primers reported in previous studies and developed in this study (Table 3 ). Approximately $40 \mathrm{ng}$ of genomic DNA was used in a $20 \mathrm{ul} \mathrm{PCR}$ reaction containing $2 \mathrm{ul}$ of primer pairs ( $10 \mathrm{pmol} / \mathrm{ul}), 2.0 \mathrm{ul}$ of $10 \mathrm{x}$ PCR buffer, $1.6 \mathrm{ul}$ of dNTP $(2.5 \mathrm{mM})$, and $0.2 \mathrm{ul}$ of Taq polymerase (5 unit/ul; Promega. USA). The reaction mixture was subjected to the following conditions: initial denaturation at $94^{\circ} \mathrm{C}$ for $5 \mathrm{~min}$, followed by 35 cycles of denaturation at $94^{\circ} \mathrm{C}$ for $30 \mathrm{~s}$, annealing at $55-60^{\circ} \mathrm{C}$ for $30 \mathrm{~s}$ and extension at $72^{\circ} \mathrm{C}$ for $45-60 \mathrm{~s}$, and final extension at $72^{\circ} \mathrm{C}$ for $10 \mathrm{~min}$. The PCR amplified products of bacterial blight ( $\mathrm{Xa3}, \mathrm{Xa}$, $\mathrm{xal} 3$ and $\mathrm{Xa} 21$ ), blast ( $\mathrm{Pi}$-b, $\mathrm{Pi}$-ta and $\mathrm{Pi-5}$ ), and brown planthopper (Bphl) resistant genes were separated on 1.5-2.0 \% agarose gel and stained with ethidium bromide. The amplified products of Xa4, xa5, and Wbph were run on a fragment capillary gel electrophoresis system (Fragment analyzer, USA) and fragments were sized and scored using PROSize 2.0 software (Fragment analyzer, USA). The amplification of $B p h 18(t)$ is performed on an Eco ${ }^{\mathrm{TM}}$ Real-Time PCR System (Illumina, San Diego, California, USA) according to the user guide manual (Illumina). Allele calling of amplified fragments of hybrid lines and control varieties were based on their respective resistance and susceptible controls. 
Table 1 List of 173 hybrid rice breeding lines and germplasms used in disease resistance analysis in this study

\begin{tabular}{|c|c|c|c|c|c|c|c|}
\hline No & Designation & Cross/Origin & Remark & No & Designation & Cross/Origin & Remark \\
\hline 1 & Damm-Noeub Sark & Cambodia & $\begin{array}{l}\text { Aromatic rice } \\
\text { (Jasmine) }\end{array}$ & 40 & IR98178-8-2-1-k1-2 & $\begin{array}{l}\text { IR86603-15-2-1-1-1-1-1-1/ } \\
\text { IR86515-4-7-2 }\end{array}$ & Restorer \\
\hline 2 & $\begin{array}{l}\text { Srau Damm-Noeub } \\
\text { Banh-Chras Kcharl }\end{array}$ & Cambodia & $\begin{array}{l}\text { Aromatic rice } \\
\text { (Jasmine) }\end{array}$ & 41 & IR98178-18-1-1-k1-2 & $\begin{array}{l}\text { IR86603-15-2-1-1-1-1-1-1/ } \\
\text { IR86515-4-7-2 }\end{array}$ & Restorer \\
\hline 3 & Saigon & Vietnam & Restorer & 42 & IR98178-18-1-1-k1-3 & $\begin{array}{l}\text { IR86603-15-2-1-1-1-1-1-1/ } \\
\text { IR86515-4-7-2 }\end{array}$ & Restorer \\
\hline 4 & Saigon Darat & Vietnam & Restorer & 43 & IR98187-30-1-1-k1-2 & $\begin{array}{l}\text { IR85508-6-1-1-1-1-1-1-1/ } \\
\text { IR86409-3-1-1-1-1-1 }\end{array}$ & Restorer \\
\hline 5 & Rening & Seoul University germplasm & Restorer & 44 & IR98187-30-1-1-k1-3 & $\begin{array}{l}\text { IR85508-6-1-1-1-1-1-1-1/ } \\
\text { IR86409-3-1-1-1-1-1 }\end{array}$ & Restorer \\
\hline 6 & Jasmin 85 & Thailand & $\begin{array}{l}\text { Aromatic rice } \\
\text { (Jasmine) }\end{array}$ & 45 & IR98194-9-2-1-k1-2 & $\begin{array}{l}\text { IR86590-22-2-2-1-3-1-1-1/ } \\
\text { IR86612-21-6-1-1-1-1-1 }\end{array}$ & Restorer \\
\hline 7 & OM 341 & Vietnam & Local variety & 46 & IR98194-9-2-1-k1-3 & $\begin{array}{l}\text { IR86590-22-2-2-1-3-1-1-1/ } \\
\text { IR86612-21-6-1-1-1-1-1 }\end{array}$ & Restorer \\
\hline 8 & OM 6312-1 & Vietnam & Local variety & 47 & IR98200-25-1-1-k1-3 & $\begin{array}{l}\text { IR86590-22-2-2-1-3-1-1-1/ } \\
\text { IR86612-21-6-1-1-1-1-1 }\end{array}$ & Restorer \\
\hline 9 & OM 6312-2 & Vietnam & Local variety & 48 & IR98200-25-1-1-k1-4 & $\begin{array}{l}\text { IR86590-22-2-2-1-3-1-1-1/ } \\
\text { IR86612-21-6-1-1-1-1-1 }\end{array}$ & Restorer \\
\hline 10 & OM 7347 & Vietnam & Local variety & 49 & IR98212-18-2-1-k1-2 & IR06A169/IR86612-26-9-5-1-1-1-1-1 & Restorer \\
\hline 11 & OM 9538 & Vietnam & Local variety & 50 & IR98229-2-2-1-k1-2 & IR08A138/IR72998-93-3-3-2R & Restorer \\
\hline 12 & $\begin{array}{l}\text { HHZ } \\
\text { 12-DT10-SAL1-DT1 }\end{array}$ & IRRI & Breeding line & 51 & IR98229-2-2-1-k1-3 & IR08A138/IR72998-93-3-3-2R & Restorer \\
\hline 13 & VD 20 & Vietnam & Restorer & 52 & IR98229-9-2-1-k1-2 & IR08A138/IR72998-93-3-3-2R & Restorer \\
\hline 14 & Anhui collection 1 & Anhui province, China & Restorer & 53 & IR98229-9-2-1-k1-3 & IR08A138/IR72998-93-3-3-2R & Restorer \\
\hline 15 & $\begin{array}{l}\text { Anhui collection } 2 \\
\text { PTGMS }\end{array}$ & Jilin Province, China & Restorer & 54 & IR98229-24-1-1-k1-2 & IR08A138/IR72998-93-3-3-2R & Restorer \\
\hline 16 & Anhui collection $3 \mathrm{R}$ & Anhui province, China & Restorer & 55 & IR98229-24-1-1-k1-3 & IR08A138/IR72998-93-3-3-2R & Restorer \\
\hline 17 & $\begin{array}{l}\text { Anhui collection } 4 \\
\text { Bulk }\end{array}$ & Anhui province, China & P/TGMS & 56 & IR98241-24-2-1-k1-2 & IR06N172/IR86612-38-2-2-1-1-1-1-1 & Restorer \\
\hline 18 & Aromatic rice $10-1$ & India & $\begin{array}{l}\text { Aromatic rice } \\
\text { (Basmati) }\end{array}$ & 57 & IR98241-24-2-1-k1-3 & IR06N172/IR86612-38-2-2-1-1-1-1-1 & Restorer \\
\hline 19 & Aromatic rice $10-2$ & India & $\begin{array}{l}\text { Aromatic rice } \\
\text { (Basmati) }\end{array}$ & 58 & IR98272-5-1-1-k1-3 & 9311/FL478(from Dr. Ismail) & Restorer \\
\hline 20 & IR101861-7-1-k1-2 & MingHui63/IR03A550 & Restorer & 59 & IR98272-5-1-1-k1-4 & 9311/FL478(from Dr. Ismail) & Restorer \\
\hline 21 & IR101861-7-1-k1-3 & MingHui63/IR03A550 & Restorer & 60 & IR98305-10-1-1-k1-3 & IR68897B/IRBB23 & maintainer, BB \\
\hline 22 & IR101861-28-1-k1-2 & MingHui63/IR03A550 & Restorer & 61 & Com collection 2-1 & Cambodia & $\begin{array}{l}\text { High yielding } \\
\text { ability }\end{array}$ \\
\hline 23 & IR101861-28-1-k1-3 & MingHui63/IR03A550 & Restorer & 62 & IR96632-1-1-2-1-k1-2 & $\begin{array}{l}\text { IR85592-7-1-1-1-5-1-1-1/ } \\
\text { WeedTolerantRice1 }\end{array}$ & Maintainer \\
\hline 24 & IR101870-12-1-k1-2 & MingHui63/IR08N103 & Restorer & 63 & IR96632-1-1-2-1-k1-3 & $\begin{array}{l}\text { IR85592-7-1-1-1-5-1-1-1/ } \\
\text { WeedTolerantRice1 }\end{array}$ & Maintainer \\
\hline 25 & IR101870-12-1-k1-3 & MingHui63/IR08N103 & Restorer & 64 & IR96701-28-5-2-1-k1-2 & IR85552-37-1-1-1-2-1-1-1/IR80555B & maintainer, BB \\
\hline 26 & IR101870-25-1-k1-2 & MingHui63/IR08N103 & Restorer & 65 & IR96701-28-5-2-1-k1-3 & IR85552-37-1-1-1-2-1-1-1/IR80555B & maintainer, BB \\
\hline 27 & IR101870-25-1-k1-3 & MingHui63/IR08N103 & Restorer & 66 & IR96701-28-5-2-1-k1-2 & IR85552-37-1-1-1-2-1-1-1/IR80555B & maintainer, BB \\
\hline 28 & IR101872-46-1-k1-2 & $\begin{array}{l}\text { MingHui63/ } \\
\text { IR86590-22-2-2-1-3-1-1-1 }\end{array}$ & Restorer & 67 & IR96701-28-5-2-1-k1-3 & IR85552-37-1-1-1-2-1-1-1/IR80555B & maintainer, BB \\
\hline 29 & IR101907-27-2-k1-2 & $\begin{array}{l}\text { IR85593-20-1-1-1-2-3-1-1-1-1/ } \\
\text { IR86522-29-4-2-1-1-1-1-1 }\end{array}$ & Restorer & 68 & IR $97727-11-1-2-2$ & $\begin{array}{l}\text { HANAREUM/NSIC RC } \\
\text { 158//HANAREUM }\end{array}$ & \\
\hline 30 & IR101907-27-2-k1-3 & $\begin{array}{l}\text { IR85593-20-1-1-1-2-3-1-1-1-1/ } \\
\text { IR86522-29-4-2-1-1-1-1-1 }\end{array}$ & Restorer & 69 & IR $97727-82-1-2-2$ & $\begin{array}{l}\text { HANAREUM/NSIC RC } \\
\text { 158//HANAREUM }\end{array}$ & \\
\hline 31 & IR98073-3-1-1-k1-3 & $\begin{array}{l}\text { IR72903-131-1-2-3R/ } \\
\text { IR85485-106-B-B-1-1-1-1 }\end{array}$ & Restorer & 70 & IR $97730-27-2-3-1$ & $\begin{array}{l}\text { SAEGAEJINMI/IR } 6 \\
\text { (PAKISTAN)//SAEGAEJINMI }\end{array}$ & \\
\hline 32 & IR98116-7-2-1-k1-2 & SACG7(GID: 2643634)/IRBB23 & Restorer, BB & 71 & BK7 6089-74-40 & Seoul University germplasm & Restorer \\
\hline 33 & IR98116-7-2-1-k1-3 & SACG7(GID: 2643634)/IRBB23 & Restorer, BB & 72 & IR2768-11-133-e & IRRI & Restorer \\
\hline 34 & IR98139-9-1-1-k1-2 & IR86505-6-15-2-1-1-1-1/IRBB60 & Restorer, BB & 73 & RPW6-13 & Seoul University germplasm & Restorer \\
\hline 35 & IR98139-9-1-1-k1-3 & IR86505-6-15-2-1-1-1-1/IRBB60 & Restorer, BB & 74 & GIIB-si 213 & Seoul University germplasm & Restorer \\
\hline 36 & IR98141-25-1-1-k1-2 & $\begin{array}{l}\text { IR86526-8-8-1-1-1-1-1/ } \\
\text { IR86555-3-3-1-1-1-1-1-1-1-1 }\end{array}$ & Restorer & 75 & IR20905-11-3-3 & IRRI & Restorer \\
\hline 37 & IR98141-25-1-1-k1-3 & $\begin{array}{l}\text { IR86526-8-8-1-1-1-1-1/ } \\
\text { IR86555-3-3-1-1-1-1-1-1-1-1 }\end{array}$ & Restorer & 76 & $\begin{array}{l}\text { J.P. } 5-\text { IR } 946-2-2-2 \\
\text { /IR1635-1F }\end{array}$ & IRRI & Restorer \\
\hline 38 & IR98161-2-1-1-k1-2 & IR86409-3-1-1-1-1-1/IRBB66 & Restorer, BB & 77 & Oksusu byeo & China & Restorer \\
\hline
\end{tabular}


Table 1 Continued

\begin{tabular}{|c|c|c|c|c|c|c|c|}
\hline No & Designation & Cross/Origin & Remark & No & Designation & Cross/Origin & Remark \\
\hline 78 & IR 68 & IRRI & Restorer & 127 & Aromatic rice $11-1$ & India & $\begin{array}{l}\text { Aromatic rice } \\
\text { (Basmati) }\end{array}$ \\
\hline 79 & IR5105-113-3 & IRRI & Restorer & 128 & Aromatic rice $11-2$ & India & $\begin{array}{l}\text { Aromatic rice } \\
\text { (Basmati) }\end{array}$ \\
\hline 80 & IR2006 & IRRI & Restorer & 129 & Aromatic rice $11-3$ & India & $\begin{array}{l}\text { Aromatic rice } \\
\text { (Basmati) }\end{array}$ \\
\hline 81 & IR2003-97-4-2 & IRRI & Restorer & 130 & Jasponica H-B-B-8-B & Selected line & $\begin{array}{l}\text { Restorer, } \\
\text { Aromatic rice }\end{array}$ \\
\hline 82 & IR2042-175-3-2-2 & IRRI & Restorer & 131 & Jasponica H-B-B-7-B & Selected line & $\begin{array}{l}\text { Restorer, } \\
\text { Aromatic rice }\end{array}$ \\
\hline 83 & IR1529-430-3 & IRRI & Restorer & 132 & Jasponica H-B-B-16-B & Selected line & $\begin{array}{l}\text { Restorer, } \\
\text { Aromatic rice }\end{array}$ \\
\hline 84 & IR1539-823-1-4 & IRRI & Restorer & 133 & Jasponica H-B-B-21-B & Selected line & $\begin{array}{l}\text { Restorer, } \\
\text { Aromatic rice }\end{array}$ \\
\hline 85 & Kianse-Wuan & China & Restorer & 134 & Jasponica H-B-B-26-B & Selected line & $\begin{array}{l}\text { Restorer, } \\
\text { Aromatic rice }\end{array}$ \\
\hline 86 & Laxmi & India & Restorer & 135 & Jasponica H-B-B-7-1 & Selected line & $\begin{array}{l}\text { Restorer, } \\
\text { Aromatic rice }\end{array}$ \\
\hline 87 & Quella-Inia & Seoul University germplasm & Restorer & 136 & Jasponica H-B-B-9-1 & Selected line & $\begin{array}{l}\text { Restorer, } \\
\text { Aromatic rice }\end{array}$ \\
\hline 88 & IR9859-5-3-3 & IRRI & Restorer & 137 & Jasponica H-B-B-12-1 & Selected line & $\begin{array}{l}\text { Restorer, } \\
\text { Aromatic rice }\end{array}$ \\
\hline 89 & CB435 & Seoul University germplasm & Restorer & 138 & Jasponica H-B-B-17-1 & Selected line & $\begin{array}{l}\text { Restorer, } \\
\text { Aromatic rice }\end{array}$ \\
\hline 90 & $\begin{array}{l}\text { IR23325-R-R-B-7-2- } \\
2\end{array}$ & IRRI & Restorer & 139 & Jasponica H-B-B-18-1 & Selected line & $\begin{array}{l}\text { Restorer, } \\
\text { Aromatic rice }\end{array}$ \\
\hline 91 & IR4457-5-3-6 & IRRI & Restorer & 140 & Jasponica H-B-B-19-1 & Selected line & $\begin{array}{l}\text { Restorer, } \\
\text { Aromatic rice }\end{array}$ \\
\hline 92 & VRH624 & Seoul University germplasm & Restorer & 141 & Jasponica H-B-B-21-1 & Selected line & $\begin{array}{l}\text { Restorer, } \\
\text { Aromatic rice }\end{array}$ \\
\hline 93 & 9019 & China & Restorer & 142 & Jasponica H-B-B-27-1 & Selected line & $\begin{array}{l}\text { Restorer, } \\
\text { Aromatic rice }\end{array}$ \\
\hline 94 & Y4037 & China & Restorer & 143 & IRRI-A29 B12 & IRRI maintainer & $\begin{array}{l}\text { Maintainer, } \\
\text { High natural } \\
\text { crossing }\end{array}$ \\
\hline 95 & K100520 & Seoul University germplasm & Restorer & 144 & IRRI-A29 B13 & IRRI maintainer & $\begin{array}{l}\text { Maintainer, } \\
\text { High natural } \\
\text { crossing }\end{array}$ \\
\hline 96 & Conde & Seoul University germplasm & Restorer & 145 & IR1487-327-1-1-3 & IRRI & Restorer \\
\hline 97 & $\mathrm{~N} 22$ & India & $\begin{array}{l}\text { Wide } \\
\text { compatibility }\end{array}$ & 146 & DF-1 & Seoul University germplasm & Restorer \\
\hline 98 & Garu & Seoul University germplasm & Restorer & 147 & Utri Rajapan & IRRI_Indonesia & Restorer \\
\hline 99 & Restorer 1 & China & Restorer & 148 & IR4547-2-1-2 & IRRI & Restorer \\
\hline 100 & Restorer 2 & China & Restorer & 149 & IR $01 \mathrm{~W} 105$ & IRRI & Restorer \\
\hline 101 & Restorer 3 & China & Restorer & 150 & IR 70 & IRRI & Restorer \\
\hline 102 & Pare panjang & Seoul University germplasm & Restorer & 151 & Tjempo Brondol & Indonesia & Restorer \\
\hline 103 & ESMET126 & Seoul University germplasm & Restorer & 152 & Burung Putar & Indonesia & Restorer \\
\hline 104 & BD 43 & Bangladesh & Restorer & 153 & Phkar Khgnei & Cambodia & $\begin{array}{l}\text { Aromatic rice } \\
\text { (Jasmine) }\end{array}$ \\
\hline 105 & BR 26 & Bangladesh & Restorer & 154 & $\begin{array}{l}\text { Damm-Noeub Phka } \\
\text { Roluoh }\end{array}$ & Cambodia & $\begin{array}{l}\text { Aromatic rice } \\
\text { (Jasmine) }\end{array}$ \\
\hline 106 & IR OM CS 2102 & IRRI- Vietnam & Restorer & 155 & Karn Dal Kbal & Cambodia & $\begin{array}{l}\text { Aromatic rice } \\
\text { (Jasmine) }\end{array}$ \\
\hline 107 & IR7760-4-8-2 & IRRI & Restorer & 156 & Thmar Ror Meal & Cambodia & $\begin{array}{l}\text { Aromatic rice } \\
\text { (Jasmine) }\end{array}$ \\
\hline 108 & TGMS & China & TGMS & 157 & KaseKam & Cambodia & $\begin{array}{l}\text { Aromatic rice } \\
\text { (Jasmine) }\end{array}$ \\
\hline 109 & Aromatic rice $1-1$ & India & $\begin{array}{l}\text { Aromatic rice } \\
\text { (Basmati) }\end{array}$ & 158 & Damm-Noeub Trar-sark & Cambodia & $\begin{array}{l}\text { Aromatic rice } \\
\text { (Jasmine) }\end{array}$ \\
\hline 110 & Aromatic rice $1-2$ & India & $\begin{array}{l}\text { Aromatic rice } \\
\text { (Basmati) }\end{array}$ & 159 & $\begin{array}{l}\text { Damm-Noeub Krar } \\
\text { Muon }\end{array}$ & Cambodia & $\begin{array}{l}\text { Aromatic rice } \\
\text { (Jasmine) }\end{array}$ \\
\hline 111 & Aromatic rice $1-3$ & India & $\begin{array}{l}\text { Aromatic rice } \\
\text { (Basmati) }\end{array}$ & 160 & Damm-Noeub Khmau & Cambodia & $\begin{array}{l}\text { Aromatic rice } \\
\text { (Jasmine) }\end{array}$ \\
\hline
\end{tabular}


Table 1 Continued

\begin{tabular}{|c|c|c|c|c|c|c|c|}
\hline No & Designation & Cross/Origin & Remark & No & Designation & Cross/Origin & Remark \\
\hline 112 & Aromatic rice 3-1 & India & $\begin{array}{l}\text { Aromatic rice } \\
\text { (Basmati) }\end{array}$ & 161 & Damm-Noeub Trar-sark & Cambodia & $\begin{array}{l}\text { Aromatic rice } \\
\text { (Jasmine) }\end{array}$ \\
\hline 113 & Aromatic rice $3-2$ & India & $\begin{array}{l}\text { Aromatic rice } \\
\text { (Basmati) }\end{array}$ & 162 & $\begin{array}{l}\text { Damm-Noeub Chherng } \\
\text { Meann }\end{array}$ & Cambodia & $\begin{array}{l}\text { Aromatic rice } \\
\text { (Jasmine) }\end{array}$ \\
\hline 114 & Aromatic rice $3-3$ & India & $\begin{array}{l}\text { Aromatic rice } \\
\text { (Basmati) }\end{array}$ & 163 & Damm-Noeub Khmau & Cambodia & $\begin{array}{l}\text { Aromatic rice } \\
\text { (Jasmine) }\end{array}$ \\
\hline 115 & Aromatic rice $5-1$ & India & $\begin{array}{l}\text { Aromatic rice } \\
\text { (Basmati) }\end{array}$ & 164 & Damm-Noeub youn & Cambodia & $\begin{array}{l}\text { Aromatic rice } \\
\text { (Jasmine) }\end{array}$ \\
\hline 116 & Aromatic rice $5-2$ & India & $\begin{array}{l}\text { Aromatic rice } \\
\text { (Basmati) }\end{array}$ & 165 & Damm-Noeub youn & Cambodia & $\begin{array}{l}\text { Aromatic rice } \\
\text { (Jasmine) }\end{array}$ \\
\hline 117 & Aromatic rice $5-3$ & India & $\begin{array}{l}\text { Aromatic rice } \\
\text { (Basmati) }\end{array}$ & 166 & Krar Harm & Cambodia & $\begin{array}{l}\text { Aromatic rice } \\
\text { (Jasmine) }\end{array}$ \\
\hline 118 & Aromatic rice $6-1$ & India & $\begin{array}{l}\text { Aromatic rice } \\
\text { (Basmati) }\end{array}$ & 167 & Damm-Noeub Khmau & Cambodia & $\begin{array}{l}\text { Aromatic rice } \\
\text { (Jasmine) }\end{array}$ \\
\hline 119 & Aromatic rice $6-2$ & India & $\begin{array}{l}\text { Aromatic rice } \\
\text { (Basmati) }\end{array}$ & 168 & $7289 \mathrm{~s}$ & IR75589-31-27-8-33S(S1)/IR102561B & TGMS \\
\hline 120 & Aromatic rice $6-3$ & India & $\begin{array}{l}\text { Aromatic rice } \\
\text { (Basmati) }\end{array}$ & 169 & $7290 \mathrm{~s}$ & IR75589-31-27-8-33S(S1)/IR102568B & TGMS \\
\hline 121 & Aromatic rice 9-1 & India & $\begin{array}{l}\text { Aromatic rice } \\
\text { (Basmati) }\end{array}$ & 170 & $7292 \mathrm{~s}$ & IR75589-31-27-8-33S(S1)/IR102758B & TGMS \\
\hline 122 & Aromatic rice $9-2$ & India & $\begin{array}{l}\text { Aromatic rice } \\
\text { (Basmati) }\end{array}$ & 171 & $7293 \mathrm{~s}$ & IR75589-31-27-8-33S(S1)/IR58025B & TGMS \\
\hline 123 & Aromatic rice 9-3 & India & $\begin{array}{l}\text { Aromatic rice } \\
\text { (Basmati) }\end{array}$ & 172 & $7306 \mathrm{~s}$ & IR75589-31-27-8-33S/IR105687B & TGMS \\
\hline 124 & Aromatic rice $10-1$ & India & $\begin{array}{l}\text { Aromatic rice } \\
\text { (Basmati) }\end{array}$ & 173 & TGMS_bulks & IRRI & TGMS \\
\hline 125 & Aromatic rice $10-2$ & India & $\begin{array}{l}\text { Aromatic rice } \\
\text { (Basmati) }\end{array}$ & & & & \\
\hline
\end{tabular}

Table 2 Information of control varieties used in several disease resistance analyses in this study

\begin{tabular}{cll}
\hline Gene & \multicolumn{1}{c}{ Resistant Controls } & Susceptible Controls \\
\hline$X a 3$ & IRBB3 & IR24 \\
$X a 4$ & IRBB4 & IR24 \\
$x a 5$ & IRBB5 & IR24 \\
$X a 7$ & IRBB7 24 \\
$x a 13$ & IRBB13 & IR24 \\
$X a 21$ & IRBB21 & IR24 \\
$P i-b$ & IRBL-b & LTH \\
$P i-t a$ & IRBL-ta(K1), IRBL-ta(CT2), & LTH \\
$P i-5$ & IRBL-ta2(Pi) & LTH \\
$B p h 1$ & IRBL_3(CP4), IRBL_5(M), IRBL_i(F5) & Dongjin, IR24 \\
$B p h 18(t)$ & Hangangchal1, IR26 & IR24, Ilpum \\
$W B P H$ & Anmi, Anda & Nipponbare, TN1
\end{tabular}

\section{Developing Bph18(t) primer for HRM}

Bph18(t)(SNP23/SNP24) was designed based on a single nucleotide variation $(\mathrm{G} / \mathrm{C})$ found on the $18,379,251$ region of the gene sequences in susceptible (HR 20654-39-3-5, IR 10 K153, IR 10K150, IR 10K152, Jinmi, Kanto 51 and Lemont) and resistant (IR65482, Anda, AG04208, SR14694-57-42-1-3-2-2, SR21733-48-1-12-3-2, Backunchal, Backyang and Chupung) cultivars. The forward and reverse primer sequences that flank the SNP region were generated using Primer 3 (v.0.4.0) (Untergasser et al. 2012; Koressaar and
Remm 2007) which were set to amplify $110 \mathrm{bp}$ of product size. To test the primer, we used it to genotype a panel of 10 resistant and 31 susceptible varieties, as shown in Fig. 1.

\section{Results}

Estimation of Genotypes for BB Resistance Genes

A total of 173 hybrid breeding lines genotyped using PCRbased markers related to Xa3, Xa4, xa5, Xa7, xa13, and Xa21 
Table 3 List of markers used for analysis of various diseases resistance

\begin{tabular}{|c|c|c|c|c|c|c|}
\hline $\begin{array}{l}\text { Disease/ } \\
\text { Insect }\end{array}$ & Gene & Marker & Type & Primer sequence $\left(5^{\prime} \rightarrow 3^{\prime}\right)$ & $\begin{array}{l}\text { Expected } \\
\text { Size (bp) }\end{array}$ & Reference \\
\hline \multirow{14}{*}{$\begin{array}{c}\text { Bacterial } \\
\text { blight (BB) }\end{array}$} & \multirow{4}{*}{$X a 3$} & \multirow{2}{*}{ BB3-Su } & Fw & CGGAGCGACACAGCTATCAT & \multirow{2}{*}{743} & \multirow{4}{*}{ Hur et al. 2013} \\
\hline & & & $\mathrm{Rv}$ & CGTGAGGTTCCCTATGGCGATT & & \\
\hline & & \multirow{2}{*}{$\mathrm{BB} 3-\mathrm{Re}$} & Fw & CCACAATGCCATGTCAGGTGGCATCCCTGCA & \multirow{2}{*}{255} & \\
\hline & & & $\mathrm{Rv}$ & AGGTGTTGGAGGATTGGCAT & & \\
\hline & \multirow{2}{*}{ Xa4 } & \multirow{2}{*}{ RM 224} & Fw & ATCGATCGATCTTCACGAGG & \multirow{2}{*}{$150 / 120$} & Chen et al. 1997; \\
\hline & & & $\mathrm{Rv}$ & TGCTATAAAAGGCATTCGGG & & McCouch et al. 2002 \\
\hline & \multirow{2}{*}{$x a 5$} & \multirow{2}{*}{ RM122 } & $\mathrm{Fw}$ & GCACTGCAACCATCAATGAATC & \multirow{2}{*}{$236 / 232$} & \multirow{2}{*}{ Chen et al. 1997} \\
\hline & & & Rv & CCTAGGAGAAACTAGCCGTCCA & & \\
\hline & \multirow{2}{*}{$X a 7$} & \multirow{2}{*}{ M5 } & Fw & CGATCTTACTGGCTCTGCAACTCTGT & \multirow{2}{*}{$294 / 1170$} & \multirow{2}{*}{ Porter et al. 2003} \\
\hline & & & $\mathrm{Rv}$ & GCATGTCTGTGTCGATTCGTCCGTACGA & & \\
\hline & \multirow{2}{*}{$x a 13$} & xa13 & Fw & GGCCATGGCTCAGTGTTTAT & \multirow{2}{*}{$1000 / 520$} & Zhang et al. 1996; \\
\hline & & prom & $\mathrm{Rv}$ & GAGCTCCAGCTCTCCAAATG & & Singh et al. 2011 \\
\hline & \multirow{2}{*}{$X a 21$} & \multirow{2}{*}{ pTA248 } & $\mathrm{Fw}$ & AGACGCGGAAGGGTGGTTCCCGGA & \multirow{2}{*}{$1000 / 750$} & \multirow{2}{*}{ Huang et al. 1997} \\
\hline & & & $\mathrm{Rv}$ & AGACGCGGTAATCGAAAGATGAAA & & \\
\hline \multirow{6}{*}{ Blast } & \multirow{2}{*}{$P i b$} & \multirow{2}{*}{$\mathrm{NSb}$} & Fw & ATCAACTCTGCCACAAAATCC & \multirow{2}{*}{629} & \multirow{2}{*}{ Kwon et al. 2008} \\
\hline & & & $\mathrm{Rv}$ & CCCATATCACCACTTGTTCCCC & & \\
\hline & \multirow{2}{*}{ Pi5 } & \multirow{2}{*}{ JJ817 } & Fw & GATATGGTTGAAAAGCTAATCTCA & \multirow{2}{*}{1450} & Kwon et al 2008 \\
\hline & & & $\mathrm{Rv}$ & ATCATTGTCCTTCATATTCAGAGT & & Kwon et al. 2008 \\
\hline & $P i-t a$ & YI 155/87 & Fw & AGCAGGTTATAAGCTAGGCC & 1042 & Jia et al $2002 \quad 2004$ \\
\hline & $P l-l a$ & & $\mathrm{Rv}$ & CTACCAACAAGTTCATCAAA & & गа el al. 2002,2004 \\
\hline & Bnhl & BeP18-3 & Fw & CGCTGCGAGAGTGTGACACT & 523 & Kim and Sohn 2005 \\
\hline $\mathrm{BPH}$ & & & $\mathrm{Rv}$ & TTGGGTTACACGGGTTTGAC & & Nim and Somin, 2005 \\
\hline & $B p h 18(t)$ & SNP23 & Fw & CGATGGATTACCCTATCACCTCAA & 110 & Develoned in this studv \\
\hline & $D p n i 0(l)$ & SNP24 & $\mathrm{Rv}$ & AACCCTCTGCACACCATCGG & 110 & Developed in this study \\
\hline WBPH & Wbph & RM8213 & Fw & AGCCCAGTGATACAAAGATG & 177 & Sun et al. 2005 \\
\hline WDPח & mopn & N1V10215 & Rv & GCGAGGAGATACCAAGAAAG & $17 /$ & Sull et al. 2005 \\
\hline
\end{tabular}

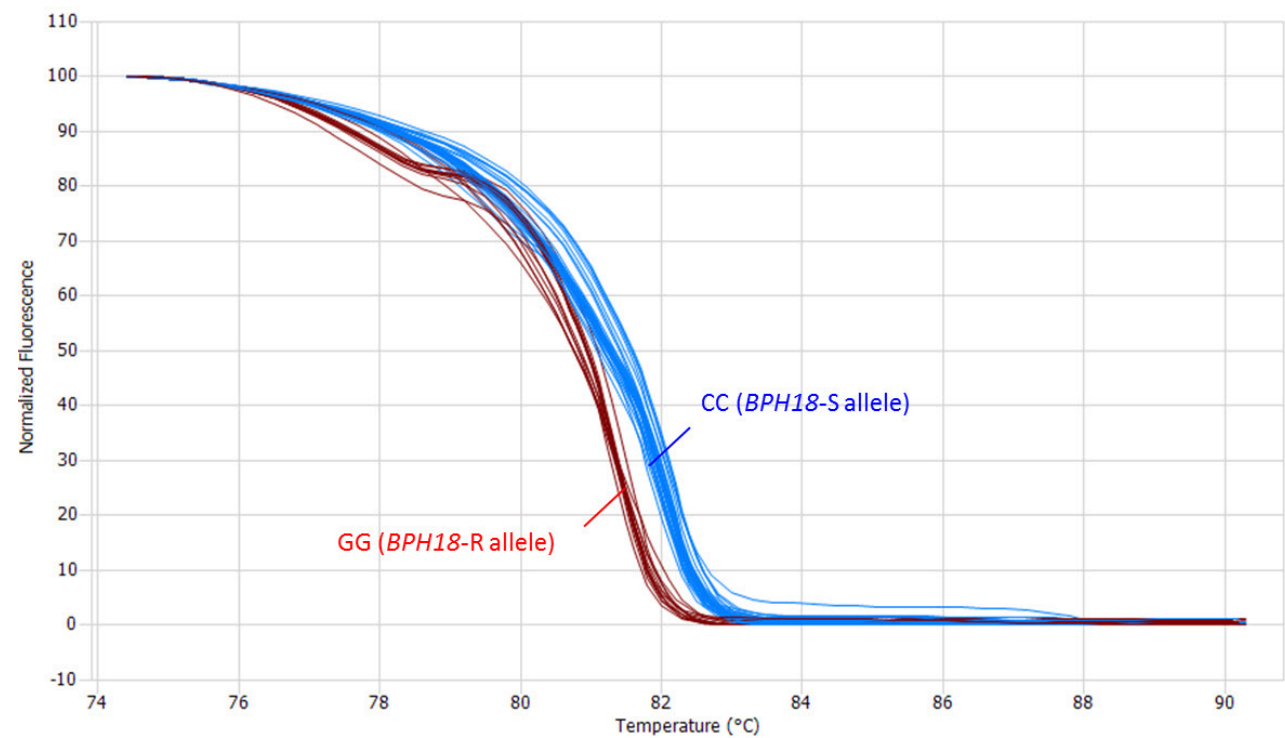

Fig. 1 HRM curve profiles of 10 resistant and 31 susceptible varieties using developed specific SNP marker for $B p h 18(t)$ in this study

genes were analyzed for fragment size differences and presence/absence of genes (Fig. 2). The percentage of rice panel identified to contain the gene was $7.5 \%$ with $\mathrm{Xa}$, $22.5 \%$ with $x a 5,0.6 \%$ with $x a 13$, and $1.2 \%$ with Xa21 (Fig. $5 \mathrm{~A}$ and Table 4). Among the hybrid breeding lines, IR98161- 2-1-1-k1-3 (IR86409-3-1-1-1-1-1/IRBB66) possessed five bacterial blight resistance genes (Xa4, xa5, Xa7, Xa13 and Xa21) while two hybrid rice lines [IR98161-2-1-1-k1-2 (IR86409-31-1-1-1-1/IRBB66) and 7292s (IR75589-31-27-8-33S(S1)/ IR102758B)] possessed three bacterial blight resistance genes 
A

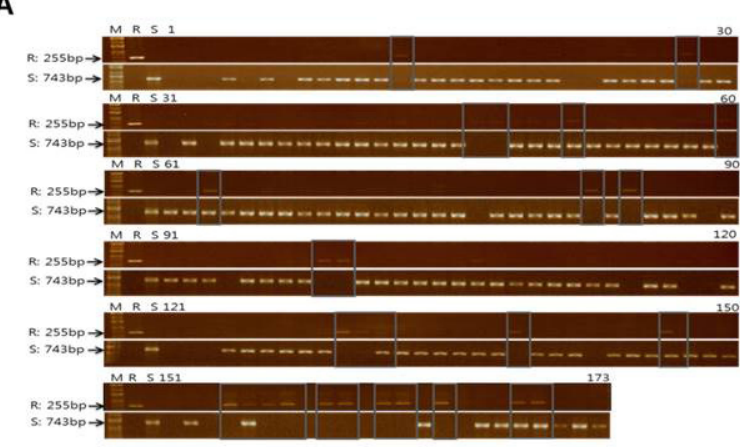

B

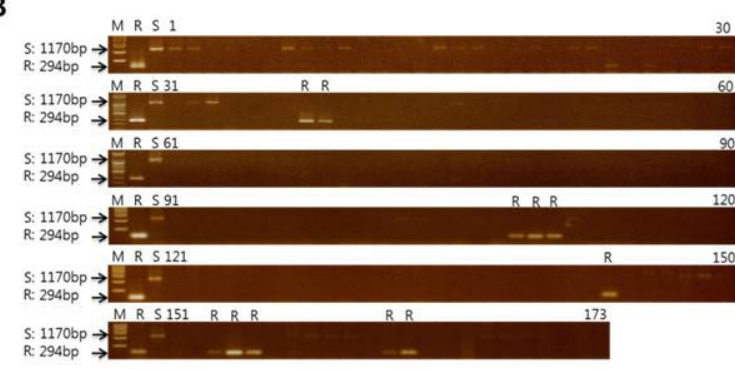

C

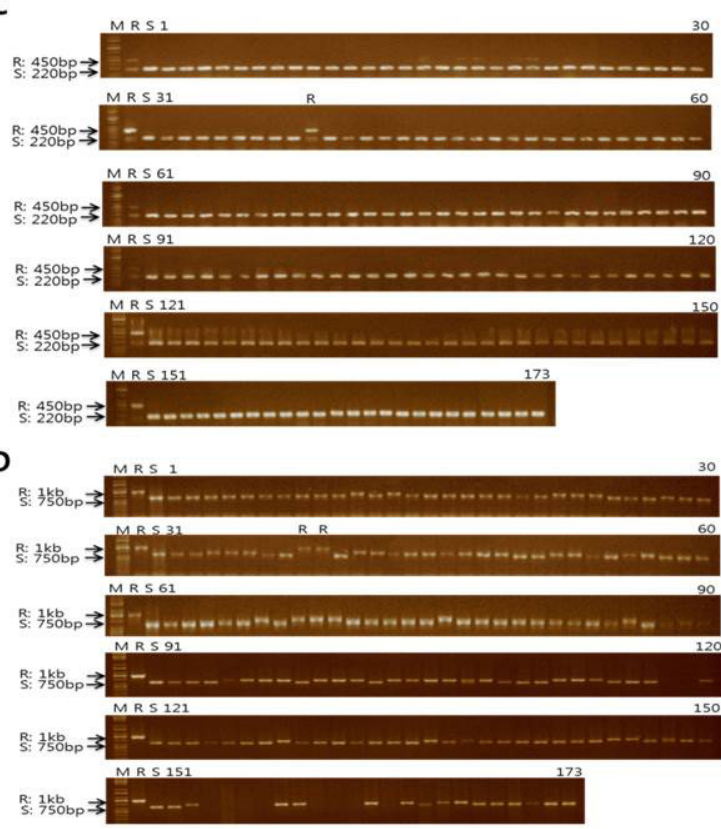

E

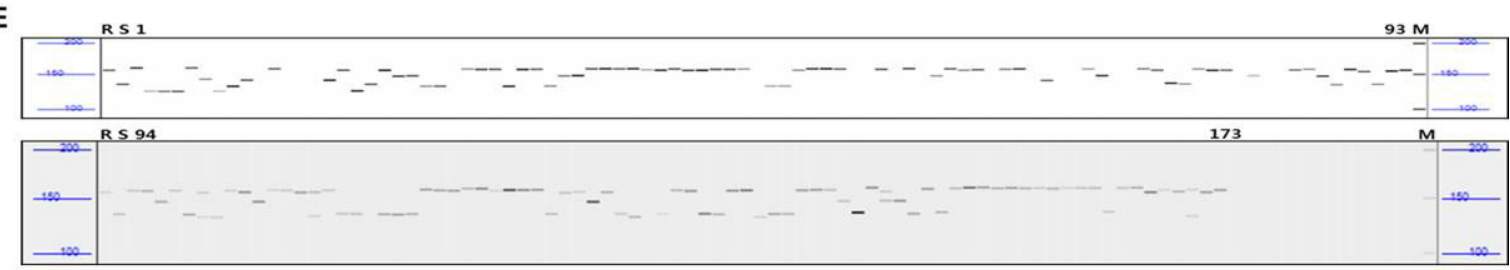

$\mathbf{F}$

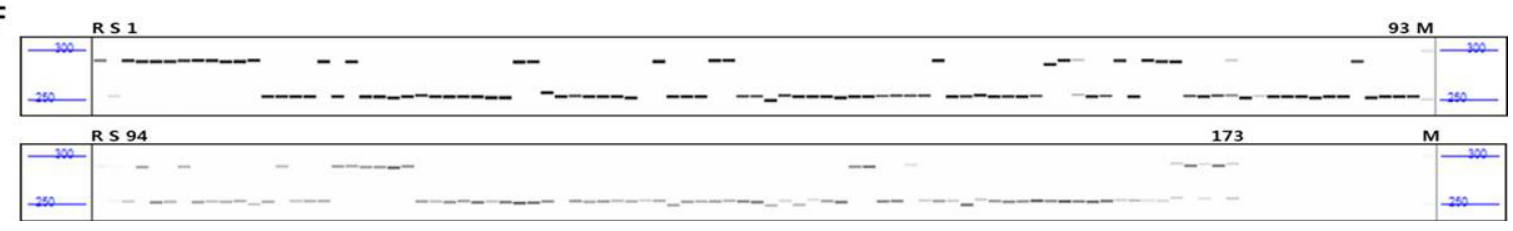

Fig. 2 PCR amplification patterns of markers that discriminate each of the six bacterial blight resistance genes in 173 hybrid rice breeding lines. A, Xa3; B, Xa7; C, xa13; D, Xa21 shows the band patterns for BB resistance specific primer on gel electrophoresis; E, Xa4 and F, $x a 5$ indicates the size differentiation by fragment analyzer gel electrophoresis. $\mathrm{R}$ and $\mathrm{S}$ in first and second lanes indicate resistant and susceptible control variety

(Xa4, Xa 7 and $X a 21$, and $X a 3, X a 4$ and $X a 5$ ). Eighty-one lines did not contain any of the BB resistance genes (Fig. 2 and Table 4). The three multiple gene containing lines were selected for developing resistant varieties using MAS.

Estimation of Genotypes for Rice Blast Resistance Genes

We examined the amplification patterns of three major rice blast resistant genes ( $P i b, P i-t a$, and $P i-5$ ) in 173 hybrid lines (Fig. 3). The tightly linked Pi-ta on chromosome 12 and $P i-5$ genes on chromosome 9 were screened with respective primers, YL155/87 and JJ817 primers. Pi-ta gene was detected in 58 (33.5\%) hybrid lines and Pi-5 gene was amplified in 35 (20.2\%) hybrid lines, while most of the lines $(68.8 \%)$ were found to carry Pib (Table 4 and Fig. 5A). According to Ramkumar et al. (2015), Pib gene is one of the major resistance genes located on chromosome 2 which confers resistance to wide range of isolates of rice blast pathogen. Of the total hybrid lines, only 11 were found to contain the three genes, $P i b, P i-5$ and Pi-ta genes (Table 4) while none was found to possess at least two genes combination. The three-gene containing lines may provide stable resistance to rice blast isolates.

\section{Estimation of Genotypes for BPH and WBPH Genes}

We further surveyed the distribution of resistant genes to brown planthopper $(\mathrm{BPH})$ and whitebacked planthopper (WBPH) in 173 hybrid rice breeding lines and germplasms (Fig. 4). Bphl was present in $20.8 \%, B p h 18$ in $27.2 \%$, and Wbph in $13.3 \%$ of the total hybrid rice breeding lines and 
A

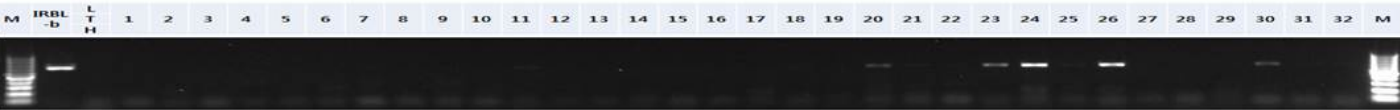

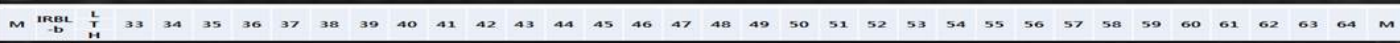
이르- - - - - - - - - - - - - - - - -

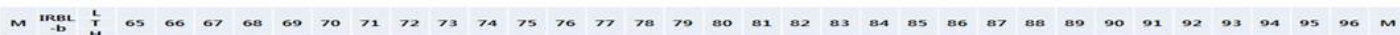

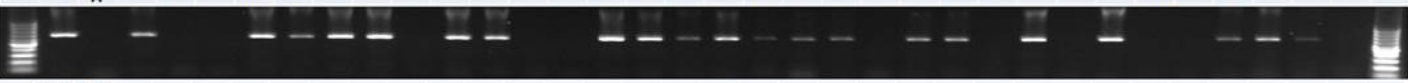

M IRB: E- - - - - - - - - - - - - - - - - - - - - - - -

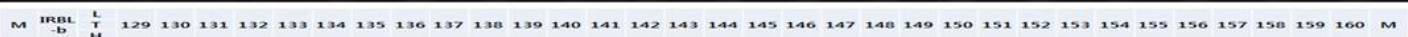
팀- - - - - - - - - - - - - - - - - -

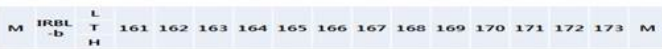
- - - - - - - - - - 릴

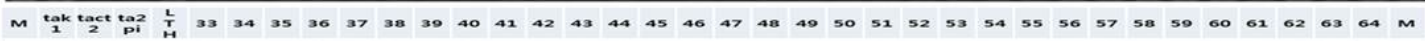

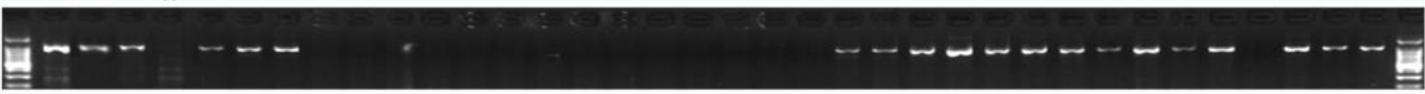

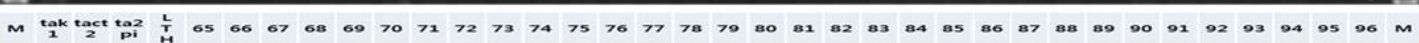

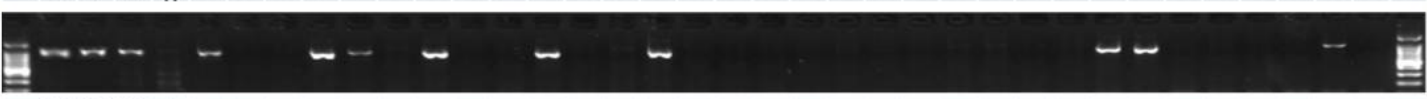

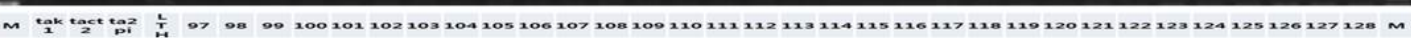

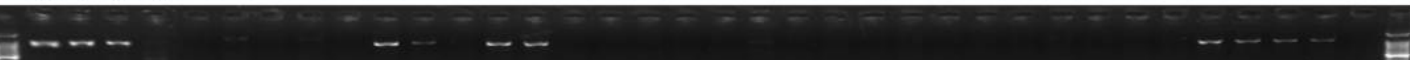

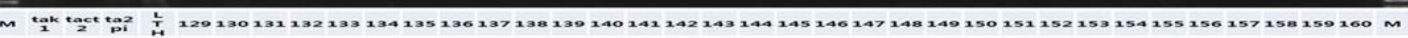

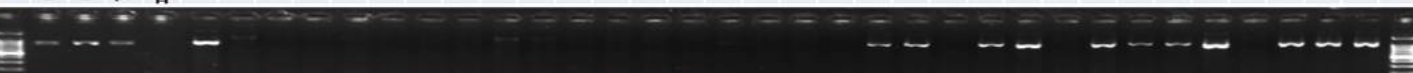

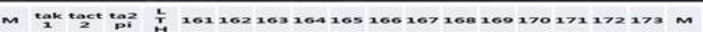

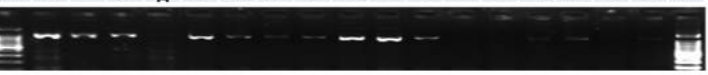

C
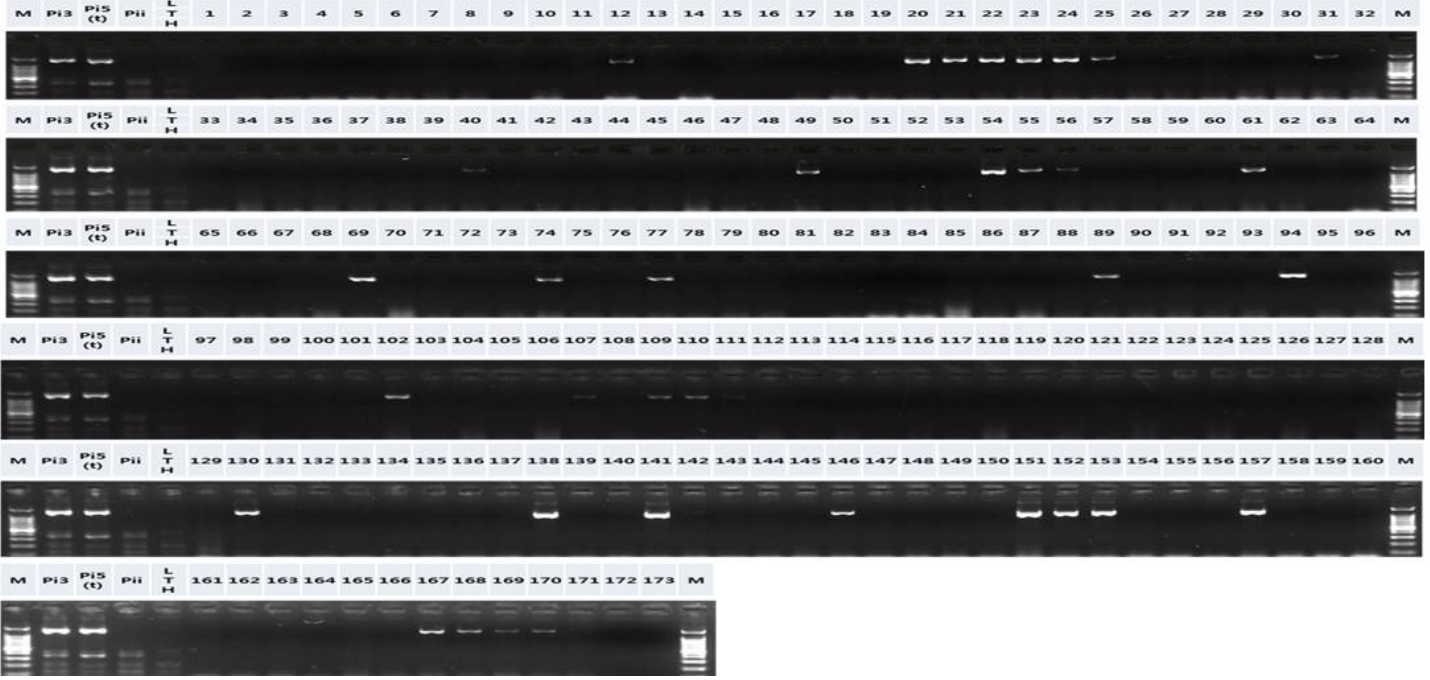

Fig. 3 PCR amplification patterns of markers that discriminate each of the three blast resistance genes in 173 hybrid breeding lines. A, Pib; B, Pi-ta; C, Pi-5 indicates the amplification patterns for each blast resistance genes in gel electrophoresis 
A

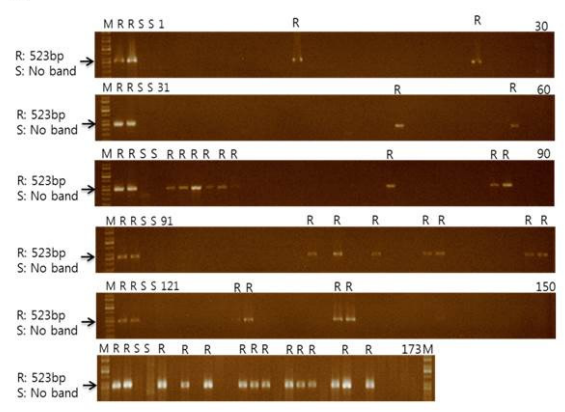

D

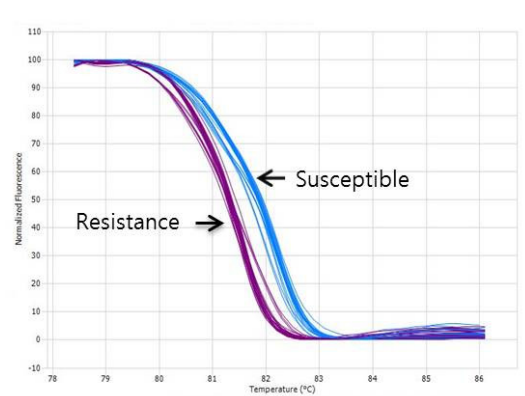

B

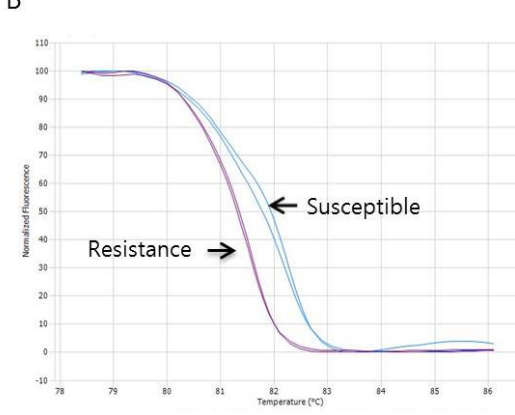

E

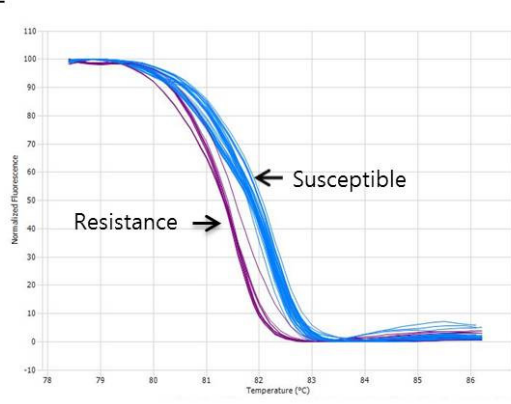

C

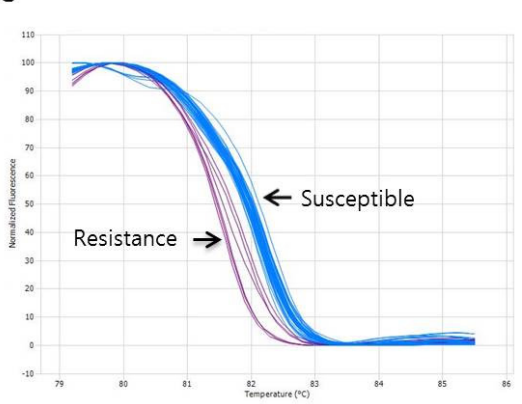

F

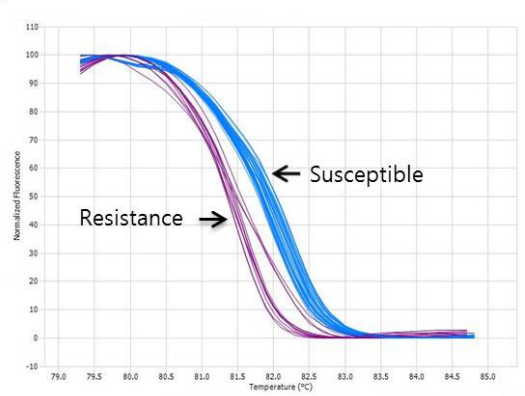

G

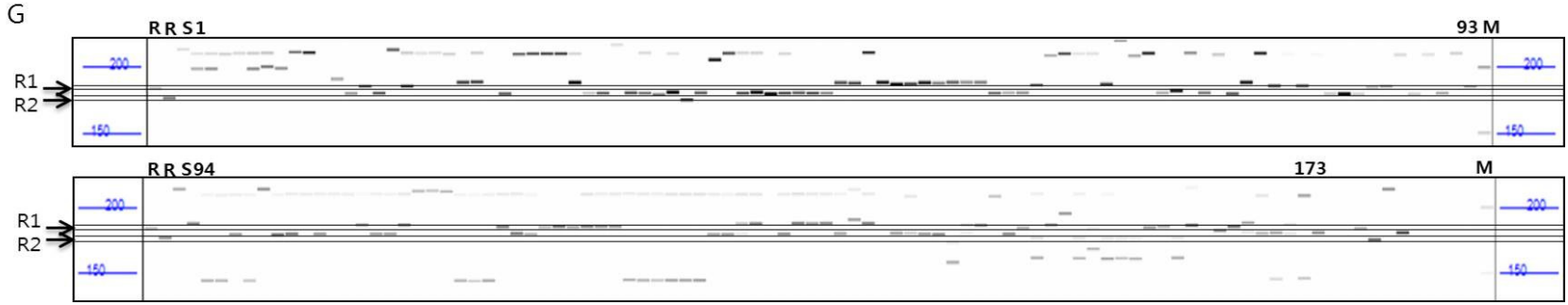

Fig. 4 PCR amplification patterns for $B p h 1$ and $W b p h$ using specific primers on agarose and fragment analyzer gel electrophoresis. A and $\mathrm{G}$ indicates $B p h 1$ and $W b p h$, respectively. HRM curve profiles of $B p h 18(t)$ specific primer in 173 rice hybrid breeding lines. B, control variety; C, 1-44; D, 45-88; E, 89-132; F, 133-173 hybrid breeding lines. R1 and R2 in G indicate resistant control variety such as Utri merah and N22, respectively

A

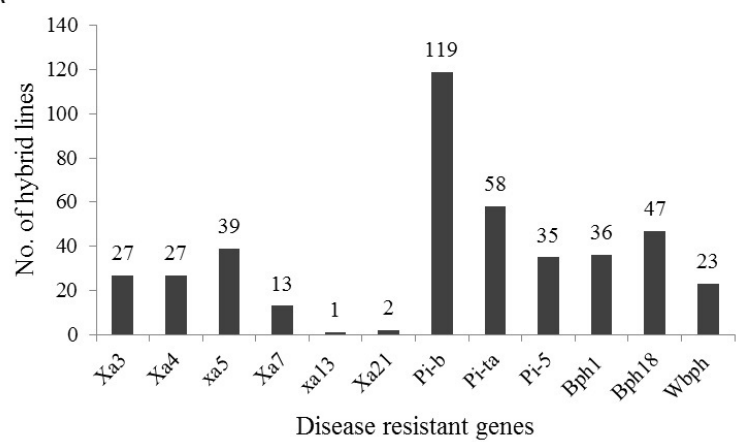

B

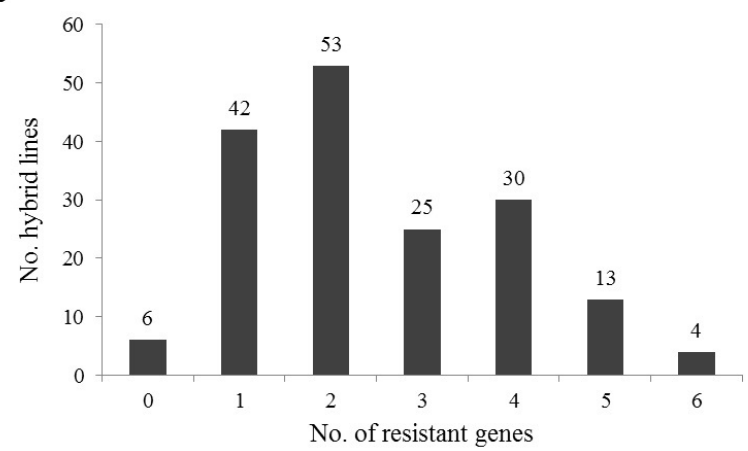

Fig. 5 A, frequency distribution of disease/insect resistant genes among 173 hybrid rice lines and B, the frequency of rice lines having different number of resistant genes

germplasms (Fig. 5A and Table 4). Among these lines, 75 lines showed the amplification of more than one of BPH and WBPH resistance genes, ranged from $1(27.2 \%)$ to $3(1.7 \%)$ genes. Three hybrid breeding lines, IR68, Laxmi, and Aromatic rice 6-3 contained all three resistance genes, which later can be used to improve the insect resistance in rice.
Estimation of Genotypes for Gene Pyramiding

Distribution of different gene combination varied greatly among the lines. Number of lines with at least two genes was found highest $(30.63 \%)$ followed by four gene containing lines (17.34\%) and five gene containing lines (7.51\%). Inter- 
Table 4 Distribution patterns of disease and insect resistant genes in 173 hybrid rice breeding lines and germplasms

\begin{tabular}{|c|c|c|c|c|c|c|c|c|c|c|c|c|c|c|c|c|c|c|}
\hline No & Entry & $\begin{array}{l}\mathrm{Xa3} \\
(\mathrm{Su})\end{array}$ & $\begin{array}{l}X a 3 \\
(\operatorname{Re})\end{array}$ & $\mathrm{Xa4}$ & $x a 5$ & $X a 7$ & $x a 13$ & $X a 21$ & $\begin{array}{c}\text { No. of } \\
R \text { genes }\end{array}$ & $P i-b$ & $P i-t a$ & $P i-5$ & $\begin{array}{c}\text { No. of } \\
R \text { genes }\end{array}$ & BPH1 & BPH18 & WBPH & $\begin{array}{l}\text { No. of } \\
\mathrm{R} \text { genes }\end{array}$ & $\begin{array}{c}\text { Total no. of } \\
\text { pyramiding R } \\
\text { genes }\end{array}$ \\
\hline 1 & 611504 & - & - & - & + & - & - & - & 1 & & & & 0 & - & - & & 0 & 1 \\
\hline 2 & 611506 & - & - & - & + & - & - & - & 1 & & & & 0 & - & - & & 0 & 1 \\
\hline 3 & 611507 & - & - & - & + & - & - & - & 1 & & & & 0 & - & - & & 0 & 1 \\
\hline 4 & 611509 & + & - & - & + & & - & - & 1 & & & & 0 & - & - & & 0 & 1 \\
\hline 5 & 611511 & - & - & - & + & & - & - & 1 & & & & 0 & - & - & & 0 & 1 \\
\hline 6 & 611513 & + & - & - & + & & - & - & 1 & & & & 0 & - & - & & 0 & 1 \\
\hline 7 & 611517 & - & - & - & + & - & - & - & 1 & & & & 0 & - & - & & 0 & 1 \\
\hline 8 & 611531 & + & - & - & + & - & - & - & 1 & & & & 0 & - & - & & 0 & 1 \\
\hline 9 & 611533 & + & - & - & + & & - & - & 1 & & & & 0 & - & - & & 0 & 1 \\
\hline 10 & 611535 & + & - & - & + & - & - & - & 1 & & & & 0 & - & - & & 0 & 1 \\
\hline 11 & 611571 & + & - & - & - & & - & - & 0 & & & & 0 & + & + & & 2 & 2 \\
\hline 12 & 611589 & + & - & - & - & & - & - & 0 & & & + & 1 & - & - & & 0 & 1 \\
\hline 13 & 611590 & - & + & - & - & & - & - & 1 & & & & 0 & - & + & + & 2 & 3 \\
\hline 14 & 611611 & + & - & - & - & & - & - & 0 & & & & 0 & - & - & & 0 & 0 \\
\hline 15 & 611626 & + & - & - & + & - & - & - & 1 & & & & 0 & - & - & & 0 & 1 \\
\hline 16 & 611631 & + & - & + & - & - & - & - & 1 & & & & 0 & - & - & + & 1 & 2 \\
\hline 17 & 611632 & + & - & - & + & - & - & - & 1 & & & & 0 & - & - & & 0 & 1 \\
\hline 18 & 611639 & + & - & - & - & & - & - & 0 & & + & & 1 & - & - & & 0 & 1 \\
\hline 19 & 611650 & + & - & + & - & & - & - & 1 & & & & 0 & - & - & & 0 & 1 \\
\hline 20 & 611674 & + & - & - & - & - & - & - & 0 & + & & + & 2 & - & - & & 0 & 2 \\
\hline 21 & 611675 & + & - & - & - & & - & - & 0 & & & + & 1 & - & - & & 0 & 1 \\
\hline 22 & 611677 & - & - & - & - & - & - & - & 0 & & & + & 1 & - & - & & 0 & 1 \\
\hline 23 & 611678 & - & - & - & - & - & - & - & 0 & + & & + & 2 & - & - & & 0 & 2 \\
\hline 24 & 611680 & + & - & - & - & + & - & - & 1 & + & & + & 2 & - & - & & 0 & 3 \\
\hline 25 & 611681 & + & - & - & - & & - & - & 0 & & & + & 1 & + & + & & 2 & 3 \\
\hline 26 & 611683 & + & - & - & - & + & - & - & 1 & + & & & 1 & - & - & & 0 & 2 \\
\hline 27 & 611684 & + & - & - & - & & - & - & 0 & & & & 0 & - & + & & 1 & 1 \\
\hline 28 & 611686 & - & + & - & - & & - & - & 1 & & & & 0 & - & - & & 0 & 1 \\
\hline 29 & 611689 & + & - & - & + & - & - & - & 1 & & & & 0 & - & - & & 0 & 1 \\
\hline 30 & 611690 & + & - & - & + & - & - & - & 1 & + & & & 1 & - & - & & 0 & 2 \\
\hline 31 & 611693 & - & - & - & - & & - & - & 0 & & + & + & 2 & - & - & & 0 & 2 \\
\hline 32 & 611697 & + & - & - & - & - & - & - & 0 & & + & & 1 & - & - & & 0 & 1 \\
\hline 33 & 611698 & - & - & - & - & - & - & - & 0 & & + & & 1 & - & - & & 0 & 1 \\
\hline 34 & 611700 & + & - & - & - & & - & - & 0 & + & + & & 2 & - & - & & 0 & 2 \\
\hline 35 & 611701 & + & - & - & - & & - & - & 0 & + & + & & 2 & - & - & & 0 & 2 \\
\hline 36 & 611703 & + & - & - & - & & - & - & 0 & + & & & 1 & - & - & + & 1 & 2 \\
\hline 37 & 611704 & + & - & - & - & & - & - & 0 & + & & & 1 & - & - & & 0 & 1 \\
\hline 38 & 611707 & + & - & + & & + & - & + & 3 & + & & & 1 & - & - & & 0 & 4 \\
\hline 39 & 611708 & + & - & + & + & + & + & + & 5 & + & & & 1 & - & - & & 0 & 6 \\
\hline 40 & 611710 & + & - & - & - & & - & - & 0 & + & & + & 2 & - & - & & 0 & 2 \\
\hline 41 & 611712 & + & - & + & - & & - & - & 1 & + & & & 1 & - & - & & 0 & 2 \\
\hline 42 & 611713 & + & - & + & - & & - & - & 1 & + & & & 1 & - & - & & 0 & 2 \\
\hline 43 & 611715 & + & - & - & + & & - & - & 1 & & & & 0 & - & - & & 0 & 1 \\
\hline 44 & 611716 & + & - & - & + & & - & - & 1 & & & & 0 & - & - & & 0 & 1 \\
\hline 45 & 611719 & + & - & - & - & & - & - & 0 & & & & 0 & - & - & & 0 & 0 \\
\hline 46 & 611720 & + & - & - & - & & - & - & 0 & & & & 0 & - & - & & 0 & 0 \\
\hline 47 & 611722 & - & + & - & - & & - & - & 1 & & & & 0 & - & - & & 0 & 1 \\
\hline 48 & 611723 & - & + & - & - & & - & - & 1 & + & & & 1 & - & - & & 0 & 2 \\
\hline 49 & 611725 & + & - & + & - & & - & - & 1 & & & + & 1 & + & + & & 2 & 4 \\
\hline 50 & 611728 & + & - & - & - & & - & - & 0 & + & + & & 2 & - & + & & 1 & 3 \\
\hline 51 & 611729 & + & - & - & - & & - & - & 0 & + & + & & 2 & - & + & & 1 & 3 \\
\hline 52 & 611731 & + & + & - & - & & - & - & 1 & + & + & & 2 & - & - & & 0 & 3 \\
\hline 53 & 611732 & + & - & - & - & & - & - & 0 & + & + & & 2 & - & - & & 0 & 2 \\
\hline 54 & 611734 & + & - & - & - & & - & - & 0 & + & + & + & 3 & - & - & & 0 & 3 \\
\hline 55 & 611735 & + & - & - & - & & - & - & 0 & + & + & + & 3 & - & + & & 1 & 4 \\
\hline 56 & 611737 & + & - & - & - & & - & - & 0 & + & + & + & 3 & - & - & & 0 & 3 \\
\hline 57 & 611738 & + & - & - & - & & - & - & 0 & + & + & & 2 & - & - & & 0 & 2 \\
\hline 58 & 611740 & + & - & - & - & & - & - & 0 & + & + & & 2 & + & + & & 2 & 4 \\
\hline 59 & 611741 & + & - & - & + & & - & - & 1 & & + & & 1 & - & - & & 0 & 2 \\
\hline 60 & 611743 & - & + & - & - & & - & - & 1 & & + & & 1 & - & - & & 0 & 2 \\
\hline 61 & 611744 & + & - & + & - & & - & - & 1 & + & & + & 2 & + & - & + & 2 & 5 \\
\hline 62 & 611747 & + & - & + & - & & - & - & 1 & + & + & & 2 & + & + & & 2 & 5 \\
\hline 63 & 611748 & + & + & - & - & & - & - & 1 & + & + & & 2 & + & + & & 2 & 5 \\
\hline 64 & 611750 & + & - & - & - & & - & - & 0 & + & + & & 2 & + & + & & 2 & 4 \\
\hline
\end{tabular}


Table 4 Continued

\begin{tabular}{|c|c|c|c|c|c|c|c|c|c|c|c|c|c|c|c|c|c|c|}
\hline No & Entry & $\begin{array}{l}X a 3 \\
(\mathrm{Su})\end{array}$ & $\begin{array}{l}X a 3 \\
(R e)\end{array}$ & Xa4 & $x a 5$ & $X a 7$ & xal3 & $X a 21$ & $\begin{array}{l}\text { No. of } \\
R \text { genes }\end{array}$ & $P i-b$ & $P i-t a$ & $P i-5$ & $\begin{array}{l}\text { No. of } \\
\text { R genes }\end{array}$ & BPH1 & BPH18 & WBPH & $\begin{array}{c}\text { No. of } \\
\text { R genes }\end{array}$ & $\begin{array}{c}\text { Total no. of } \\
\text { pyramiding R } \\
\text { genes }\end{array}$ \\
\hline 65 & 611751 & + & - & - & - & & - & - & 0 & + & + & & 2 & + & + & & 2 & 4 \\
\hline 66 & 611525 & + & - & - & - & & - & - & 0 & & & & 0 & + & + & & 2 & 2 \\
\hline 67 & 611527 & + & - & - & + & & - & - & 1 & & & & 0 & - & - & & 0 & 1 \\
\hline 68 & 611809 & + & - & - & + & & - & - & 1 & + & + & & 2 & - & + & & 1 & 4 \\
\hline 69 & 611810 & + & - & - & + & & - & - & 1 & + & + & + & 3 & - & + & & 1 & 5 \\
\hline 70 & 611811 & + & - & - & - & & - & - & 0 & + & & & 1 & - & - & & 0 & 1 \\
\hline 71 & 611815 & + & - & - & - & & - & - & 0 & + & + & & 2 & - & - & & 0 & 2 \\
\hline 72 & 611529 & + & - & - & + & & - & - & 1 & & & & 0 & - & - & & 0 & 1 \\
\hline 73 & 611817 & + & - & - & - & & - & - & 0 & + & & & 1 & - & + & & 1 & 2 \\
\hline 74 & 611818 & + & - & - & + & & - & - & 1 & + & + & + & 3 & - & + & & 1 & 5 \\
\hline 75 & 611819 & + & - & + & + & & - & - & 2 & & & & 0 & - & + & & 1 & 3 \\
\hline 76 & 611820 & + & - & - & + & & - & - & 1 & & & & 0 & - & - & & 0 & 1 \\
\hline 77 & 611821 & - & - & - & - & & - & - & 0 & + & + & + & 3 & - & + & & 1 & 4 \\
\hline 78 & 611822 & + & - & - & - & & - & - & 0 & + & & & 1 & + & + & + & 3 & 4 \\
\hline 79 & 611823 & + & - & + & - & & - & - & 1 & + & & & 1 & - & + & & 1 & 3 \\
\hline 80 & 611824 & + & - & + & + & & - & - & 2 & + & & & 1 & - & + & + & 2 & 5 \\
\hline 81 & 611825 & + & - & - & - & & - & - & 0 & + & & & 1 & - & + & & 1 & 2 \\
\hline 82 & 611826 & + & - & - & - & & - & - & 0 & + & & & 1 & - & - & & 0 & 1 \\
\hline 83 & 611827 & - & + & - & - & & - & - & 1 & + & & & 1 & - & + & & 1 & 3 \\
\hline 84 & 611828 & + & - & - & - & & - & - & 0 & & & & 0 & - & - & & 0 & 0 \\
\hline 85 & 611829 & - & + & + & - & & - & - & 2 & + & & & 1 & - & + & + & 2 & 5 \\
\hline 86 & 611830 & + & - & - & - & & - & - & 0 & + & & & 1 & + & + & + & 3 & 4 \\
\hline 87 & 611831 & + & - & - & - & & - & - & 0 & & & & 0 & + & + & & 2 & 2 \\
\hline 88 & 611832 & + & - & - & - & & - & - & 0 & + & & & 1 & - & - & & 0 & 1 \\
\hline 89 & 611833 & - & - & - & + & & - & - & 1 & & + & + & 2 & - & + & & 1 & 4 \\
\hline 90 & 611834 & + & - & + & - & & - & - & 1 & + & + & & 2 & - & + & & 1 & 4 \\
\hline 91 & 611835 & + & - & - & - & & - & - & 0 & & & & 0 & - & - & & 0 & 0 \\
\hline 92 & 611836 & + & - & + & - & & - & - & 1 & & & & 0 & - & - & + & 1 & 2 \\
\hline 93 & 611837 & + & - & + & - & & - & - & 1 & + & & & 1 & - & - & & 0 & 2 \\
\hline 94 & 611838 & - & - & - & - & & - & - & 0 & + & & + & 2 & - & - & & 0 & 2 \\
\hline 95 & 611839 & + & - & - & + & & - & - & 1 & + & + & & 2 & - & + & & 1 & 4 \\
\hline 96 & 611840 & + & - & - & - & & - & - & 0 & & & & 0 & - & - & & 0 & 0 \\
\hline 97 & 611841 & + & - & - & - & & - & - & 0 & + & & & 1 & - & + & & 1 & 2 \\
\hline 98 & 611842 & + & - & - & + & & - & - & 1 & + & & & 1 & - & - & & 0 & 2 \\
\hline 99 & 611843 & - & + & + & - & & - & - & 2 & + & & & 1 & - & - & & 0 & 3 \\
\hline 100 & 611844 & - & + & - & - & & - & - & 1 & + & & & 1 & - & - & & 0 & 2 \\
\hline 101 & 611845 & + & - & - & - & & - & - & 0 & + & & & 1 & - & + & & 1 & 2 \\
\hline 102 & 611846 & + & - & + & - & & - & - & 1 & + & + & + & 3 & + & - & & 1 & 5 \\
\hline 103 & 611847 & + & - & - & - & & - & - & 0 & + & + & & 2 & - & - & & 0 & 2 \\
\hline 104 & 611848 & + & - & - & - & & - & - & 0 & + & & & 1 & + & + & & 2 & 3 \\
\hline 105 & 611849 & + & - & - & + & & - & - & 1 & + & + & & 2 & - & - & + & 1 & 4 \\
\hline 106 & 611850 & + & - & + & - & & - & - & 1 & + & + & & 2 & - & + & & 1 & 4 \\
\hline 107 & 611851 & + & - & + & - & & - & - & 1 & + & & + & 2 & + & + & & 2 & 5 \\
\hline 108 & 611852 & + & - & - & - & & - & - & 0 & + & & & 1 & - & - & + & 1 & 2 \\
\hline 109 & 611853 & + & - & - & + & + & - & - & 2 & + & & + & 2 & - & - & & 0 & 4 \\
\hline 110 & 611854 & + & - & - & + & + & - & - & 2 & + & & + & 2 & - & - & & 0 & 4 \\
\hline 111 & 611855 & + & - & - & + & + & - & - & 2 & + & & & 1 & + & - & & 1 & 4 \\
\hline 112 & 611856 & + & - & - & + & & - & - & 1 & + & & & 1 & + & - & & 1 & 3 \\
\hline 113 & 611857 & + & - & - & + & & - & - & 1 & + & & & 1 & - & - & & 0 & 2 \\
\hline 114 & 611858 & + & - & - & + & & - & - & 1 & + & & & 1 & - & - & & 0 & 2 \\
\hline 115 & 611859 & - & - & - & - & & - & - & 0 & + & & & 1 & - & - & + & 1 & 2 \\
\hline 116 & 611860 & + & - & - & - & & - & - & 0 & + & & & 1 & - & - & & 0 & 1 \\
\hline 117 & 611861 & + & - & - & - & & - & - & 0 & + & & & 1 & - & - & & 0 & 1 \\
\hline 118 & 611862 & - & - & - & - & & - & - & 0 & + & & & 1 & - & - & + & 1 & 2 \\
\hline 119 & 611863 & - & - & - & - & & - & - & 0 & + & & & 1 & + & - & + & 2 & 3 \\
\hline 120 & 611864 & + & - & - & - & & - & - & 0 & + & & & 1 & + & + & + & 3 & 4 \\
\hline 121 & 611865 & - & - & - & - & & - & - & 0 & + & & & 1 & - & - & + & 1 & 2 \\
\hline 122 & 611866 & - & - & - & - & & - & - & 0 & + & & & 1 & - & - & + & 1 & 2 \\
\hline 123 & 611867 & - & - & - & - & & - & - & 0 & + & & & 1 & - & - & + & 1 & 2 \\
\hline 124 & 611868 & + & - & - & - & & - & - & 0 & + & + & & 2 & - & - & & 0 & 2 \\
\hline 125 & 611869 & + & - & + & & & - & - & 1 & + & + & & 2 & - & - & & 0 & 3 \\
\hline 126 & 611870 & + & - & + & - & & - & - & 1 & + & + & & 2 & + & - & & 1 & 4 \\
\hline 127 & 611871 & + & - & - & - & & - & - & 0 & + & + & & 2 & + & + & & 2 & 4 \\
\hline 128 & 611872 & + & - & + & - & & - & - & 1 & + & & & 1 & - & - & & 0 & 2 \\
\hline
\end{tabular}


Table 4 Continued

\begin{tabular}{|c|c|c|c|c|c|c|c|c|c|c|c|c|c|c|c|c|c|c|}
\hline No & Entry & $\begin{array}{l}\mathrm{Xa3} \\
(\mathrm{Su})\end{array}$ & $\begin{array}{l}X a 3 \\
(R e)\end{array}$ & Xa4 & $x a 5$ & $X a 7$ & $x a 13$ & $X a 21$ & $\begin{array}{c}\text { No. of } \\
\text { R genes }\end{array}$ & $P i-b$ & $P i-t a$ & $P i-5$ & $\begin{array}{c}\text { No. of } \\
\mathrm{R} \text { genes }\end{array}$ & BPH1 & BPH18 & WBPH & $\begin{array}{c}\text { No. of } \\
R \text { genes }\end{array}$ & $\begin{array}{c}\text { Total no. of } \\
\text { pyramiding R } \\
\text { genes }\end{array}$ \\
\hline 129 & 611873 & + & - & - & - & & - & - & 0 & + & + & & 2 & - & - & & 0 & 2 \\
\hline 130 & 611874 & - & + & - & - & & - & - & 1 & + & & + & 2 & - & - & & 0 & 3 \\
\hline 131 & 611875 & - & + & - & - & & - & - & 1 & + & & & 1 & - & - & & 0 & 2 \\
\hline 132 & 611876 & + & + & - & - & & - & - & 1 & + & & & 1 & - & - & & 0 & 2 \\
\hline 133 & 611877 & + & - & - & - & & - & - & 0 & + & & & 1 & - & - & & 0 & 1 \\
\hline 134 & 611878 & + & - & - & - & & - & - & 0 & + & & & 1 & + & + & & 2 & 3 \\
\hline 135 & 611879 & + & - & - & - & & - & - & 0 & + & & & 1 & + & + & & 2 & 3 \\
\hline 136 & 611880 & + & - & - & - & & - & - & 0 & + & & & 1 & - & - & & 0 & 1 \\
\hline 137 & 611881 & + & - & - & - & & - & - & 0 & + & & & 1 & - & - & & 0 & 1 \\
\hline 138 & 611882 & + & - & - & - & & - & - & 0 & + & & + & 2 & - & - & & 0 & 2 \\
\hline 139 & 611883 & - & + & - & - & & - & - & 1 & + & & & 1 & - & - & & 0 & 2 \\
\hline 140 & 611884 & + & - & - & - & & - & - & 0 & + & & & 1 & - & - & & 0 & 1 \\
\hline 141 & 611885 & + & - & - & - & & - & - & 0 & + & & + & 2 & - & - & & 0 & 2 \\
\hline 142 & 611886 & + & - & - & - & & - & - & 0 & + & & & 1 & - & - & & 0 & 1 \\
\hline 143 & 611887 & - & - & - & - & & - & - & 0 & + & & & 1 & - & - & & 0 & 1 \\
\hline 144 & 611888 & + & - & - & - & + & - & - & 1 & + & & & 1 & - & - & & 0 & 2 \\
\hline 145 & 611889 & + & - & - & - & & - & - & 0 & + & & & 1 & - & - & & 0 & 1 \\
\hline 146 & 611890 & + & - & - & + & - & - & - & 1 & + & & + & 2 & - & - & & 0 & 3 \\
\hline 147 & 611891 & + & + & - & + & - & - & - & 2 & & + & & 1 & - & - & & 0 & 3 \\
\hline 148 & 611892 & + & - & + & - & - & - & - & 1 & + & + & & 2 & - & + & & 1 & 4 \\
\hline 149 & 611893 & + & - & - & - & - & - & - & 0 & + & & & 1 & - & - & & 0 & 1 \\
\hline 150 & 611894 & + & - & - & + & & - & - & 1 & + & + & & 2 & - & + & & 1 & 4 \\
\hline 151 & 611895 & - & - & - & - & & - & - & 0 & + & + & + & 3 & + & - & + & 2 & 5 \\
\hline 152 & 611896 & + & - & - & - & & - & - & 0 & + & & + & 2 & - & - & & 0 & 2 \\
\hline 153 & 611897 & - & - & - & - & + & - & & 1 & + & + & + & 3 & + & - & & 1 & 5 \\
\hline 154 & 611898 & - & + & - & - & + & - & & 2 & & + & & 1 & - & - & & 0 & 3 \\
\hline 155 & 611899 & + & + & - & - & + & - & & 2 & & + & & 1 & + & - & & 1 & 4 \\
\hline 156 & 611900 & - & + & - & - & & - & & 1 & & + & & 1 & - & - & & 0 & 2 \\
\hline 157 & 611901 & - & + & - & - & & - & - & 1 & & & + & 1 & - & - & & 0 & 2 \\
\hline 158 & 611902 & - & - & - & - & - & - & - & 0 & + & + & & 2 & + & - & & 1 & 3 \\
\hline 159 & 611903 & - & + & - & - & - & - & & 1 & + & + & & 2 & + & - & & 1 & 4 \\
\hline 160 & 611904 & - & + & - & - & - & - & & 1 & + & + & & 2 & + & - & + & 2 & 5 \\
\hline 161 & 611905 & - & - & - & - & & - & & 0 & + & + & & 2 & - & - & + & 1 & 3 \\
\hline 162 & 611906 & - & + & - & - & + & - & - & 2 & + & + & & 2 & + & - & & 1 & 5 \\
\hline 163 & 611907 & - & + & - & - & + & - & & 2 & + & + & & 2 & + & - & + & 2 & 6 \\
\hline 164 & 611908 & + & - & - & - & & - & - & 0 & & + & & 1 & + & - & & 1 & 2 \\
\hline 165 & 611909 & - & + & - & - & & - & - & 1 & & + & & 1 & - & - & & 0 & 2 \\
\hline 166 & 611910 & - & - & - & - & & - & - & 0 & + & + & & 2 & + & - & + & 2 & 4 \\
\hline 167 & 611911 & + & - & - & - & - & - & - & 0 & + & + & + & 3 & + & - & & 1 & 4 \\
\hline 168 & 611912 & + & - & + & - & - & - & - & 1 & + & & + & 2 & - & + & & 1 & 4 \\
\hline 169 & 611913 & + & + & - & + & & - & - & 2 & + & & + & 2 & + & + & & 2 & 6 \\
\hline 170 & 611914 & + & + & + & + & & - & - & 3 & + & + & + & 3 & - & - & & 0 & 6 \\
\hline 171 & 611915 & + & - & - & + & & - & - & 1 & + & + & & 2 & - & + & & 1 & 4 \\
\hline 172 & 611916 & + & - & + & + & & - & - & 2 & + & & & 1 & - & + & & 1 & 4 \\
\hline 173 & 611917 & + & - & - & + & & - & - & 1 & + & & & 1 & - & + & & 1 & 3 \\
\hline
\end{tabular}

+ : Positive response, -: negative response

estingly in this study, we were able to identify lines that contain up to six different resistance genes. These include IR981612-1-1-k1-3, Damm-Noeub Khmau, 7290s, and 7292s (Table 5). These results prove that it is possible to develop hybrid lines with gene pyramiding through marker-assisted breeding approach.

\section{Discussion}

Cultivated crops are exposed to different stress factors. Climate change by increasing temperature affects the habitat range of pathogens and pests, which can facilitate spread of pathogens (Luck et al. 2011; Madgwick et al. 2011). Biotic stress adversely affect plant growth, yield losses, and nutritional values (Porter and Semenov 2005), as well as seed quality of crops. Although conventional breeding is an effective method to develop resistance rice variety, it takes a lot of time to develop a new rice variety. Cross-breeding via marker-assisted selection (MAS) is expected to play a role for the development and improvement of broad-spectrum stress-tolerant crops (Nogoy et al. 2016). Therefore, we investigated the amplification patterns of resistance genes against various biotic stresses such as bacterial blight, blast and brown planthopper pests to 
Table 5 List of hybrid breeding lines with six different disease resistance genes

\begin{tabular}{|c|c|c|c|c|c|c|c|}
\hline \multirow[t]{2}{*}{ Gene combination } & \multirow{2}{*}{$\begin{array}{c}\text { No. of breeding lines } \\
39\end{array}$} & \multicolumn{6}{|c|}{ Resistance genes } \\
\hline & & $\mathrm{Xa4}$ & $x a 5$ & $X a 7$ & $x a 13$ & $X a 21$ & $P i-b$ \\
\hline & 163 & $X a 3$ & $X a 7$ & $P i-b$ & $P i-t a$ & Bphl & Wbph \\
\hline 6 genes & 169 & $X a 3$ & $x a 5$ & $P i-b$ & $P i-5$ & Bphl & $B p h 18(t)$ \\
\hline & 170 & $X a 3$ & $\mathrm{Xa4}$ & $x a 5$ & $P i-b$ & $P i-t a$ & $P i-5$ \\
\hline & 61 & Xa4 & $P i-b$ & $P i-5$ & Bph1 & Wbph & \\
\hline & 62 & $\mathrm{Xa4}$ & $P i-b$ & $P i-5$ & Bphl & $B p h 18(t)$ & \\
\hline & 63 & $X a 3$ & $P i-b$ & $P i-t a$ & Bph1 & $B p h 18(t)$ & \\
\hline & 69 & $x a 5$ & $P i-b$ & $P i-t a$ & $P i-5$ & $B p h 18(t)$ & \\
\hline & 74 & $x a 5$ & $P i-b$ & $P i-t a$ & $P i-5$ & $B p h 18(t)$ & \\
\hline & 80 & $\mathrm{Xa4}$ & $x a 5$ & $P i-b$ & $B p h 18(t)$ & Wbph & \\
\hline 5 genes & 85 & $X a 3$ & $\mathrm{Xa4}$ & $P i-b$ & $B p h 18(t)$ & Wbph & \\
\hline & 102 & $X a 4$ & $P i-b$ & $P i-t a$ & $P i-5$ & $B p h 18(t)$ & \\
\hline & 107 & $\mathrm{Xa4}$ & $P i-b$ & $P i-5$ & Bphl & $B p h 18(t)$ & \\
\hline & 151 & $P i-b$ & $P i-t a$ & $P i-5$ & Bph1 & Wbph & \\
\hline & 153 & $X a 7$ & $P i-b$ & $P i-t a$ & $P i-5$ & Bph1 & \\
\hline & 160 & $\mathrm{Xa3}$ & $P i-b$ & Pi-ta & Bphl & Wbph & \\
\hline & 162 & $X a 3$ & $\mathrm{Xa} 7$ & $P i-b$ & $P i-t a$ & Bphl & \\
\hline
\end{tabular}

genotype 173 hybrid rice lines. It is important to screen candidate genetic resources in rice cross breeding lines through genotyping because it will help breeders to maintain several small base lines having resistance to biotic stress. Furthermore, the use of markers enables the usage and maintenance of diverse resistance genes, analysis of variation, and selection for pyramided genes (Lammerts van Bueren et al. 2010).

In this study, we report the distribution of biotic stress resistance genes such as dominant ( $X a 3, X a 4, X a 7$, and $X a 21)$ and recessive ( $x a 5$ and $x a 13$ ) BB-resistance genes, rice blast (Pib, Pi-5, and Pi-ta), and BPH (Bphl, Bph18 and Wbph) resistance genes in hybrid breeding lines. A total of 173 hybrid rice breeding lines and germplasms were used for the screening of those lines with different resistance genes though MAS-based pyramiding approaches. We analyzed the distribution and genetic differences of $\mathrm{BB}$ resistant genes using six major resistant markers related to Xa3, Xa4, xa5,Xa7, xa13 and $X a 21$ genes. The results revealed that only $0.6 \%$ and $1.2 \%$ of the hybrid lines have $x a 13$ and Xa21, respectively. However, we were also able to identify lines such as IR98161-2-1-1-k1-3 which contained five genes (Xa4, Xa5, Xa7, Xa13 and Xa21), and IR98161-2-1-1-k1-2 and 7292s which possessed three respective gene combinations ( $X a 4, X a 7$ and $X a 21$, and $X a 3$, $X a 4$ and $x a 5$ ) (Table 4). Kinoshita (1995) reported that the combination of resistance genes into rice varieties is good way to develop durable resistance to BB disease. Recently, Pradhan et al. (2015) cited that a three-gene combination appeared to be the most effective with Xa21 contributing the largest component of resistance to BB. Therefore, in our future studies, we will use the identified hybrid lines with at least three gene combinations for phenotypic selection.

According to the report of Singh et al. (2015), several genes for blast resistance were found and effectively used to control rice blast disease in rice breeding and genetic studies (Chen et al. 2005; Ballini et al. 2008; Koide et al. 2009), and many blast resistant varieties have been developed. We used three major rice blast resistant genes, $P i b, P i-t a$, and $P i-5$ to confirm the distribution of resistance genes for improving rice blast resistance and multiple-resistance efficiency. Our results showed that $P i-t a$ on chromosome 12 was present in $33.5 \%$ of the hybrid rice lines while $\mathrm{Pi}-5$ gene on chromosome 9 was amplified in $20.2 \%$ of 173 hybrid rice lines. Moreover, Pib gene in chromosome 2 was present in $68.8 \%$ of the total hybrid lines. Ramkumar et al. (2015) reported that $P i b$ gene is a major resistance gene and offers resistance to wide range of isolates in India. Out of these hybrid lines, only 11 lines possessed three genes, $P i b, P i-5$ and $P i-t a$, which may be expected to provide high level of resistance against rice blast isolates, because $P i b$ is one of significant rice blast resistant genes (Ramkumar et al. 2015; Wang et al. 1999).

Previous results have been reported that brown planthopper is a destructive phloem sap sucking pest of rice which has negative effect both qualitative and quantitative (Jena et al. 2006). In this study, we searched for hybrid lines having resistant genes for brown plant hopper, namely, $B p h 1, B p h 18(t)$, and $W b p h$ in 173 hybrid rice lines. Bphl was present in 20.8\%, Bph 18 in $27.2 \%$, and $W b p h$ in $13.3 \%$ of the total hybrid lines. Among these lines, IR68, Laxmi, and Aromatic rice 6-3 have all three resistance genes (Table 4), which will be used in the future for phenotypic analysis.

In summary, we investigated hybrid rice lines with multiple- 
resistance to biotic disease and insect pests using DNA-based markers. Our results showed that most of the hybrid breeding lines contained one to four different resistant genes. We identified four lines harboring the maximum number of six resistance genes out of 12 resistance genes used and 13 lines with five resistant genes. The four lines were IR98161-2-1-1-k1-3, DammNoeub Khmau, 7290s, and 7292s lines (Table 5). These lines carrying a stack of six-genes are expected to provide higher level of multiple- resistance to biotic stresses. The information obtained and the selected lines with various resistance genes could be used to further facilitate rice disease resistance breeding especially in hybrid rice breeding programs. Available molecular analysis and transcriptome analysis of the various different genes present in each hybrid line may be able to propose a generalized stress response or points of cross-talk between signaling pathways (Atkinson and Urwin, 2012). Lastly, field performance and phenotypic reactions of the identified lines carrying multiple stack of genes in this study need to be verified to provide strong recommendations for use in hybrid rice breeding programs.

\section{Acknowledgments}

This work was supported by Golden Seed Project (No. 2130031-04-4-SB220) and by Agri-Bio industry Technology Development Program (313043-03-3-HD030), Ministry of Agriculture, Food and Rural Affairs (MAFRA), Republic of Korea.

\section{References}

Atkinson NJ, Urwin PE (2012) The interaction of plant biotic and abiotic stresses: from genes to the field. J. Exp. Bot. 63: 3523-3543

Ballini E, Morel JB, Droc G, Price A, Courtois B, Notteghem JL, Tharreau D (2008) A genome-wide meta-analysis of rice blast resistance genes and quantitative trait loci provides new insights into partial and complete resistance. Mol. Plant Microbe Interact. 21:859-868

Bonman JM, Estrada BA, Denton RJN (1986) Blast management with rice cultivar mixture. In: Progress in Upland Rice Research. Proceedings of the 2nd International Upland Rice Conference, 1985, Jakarta. IRRI, Los Banos, Philippines, 375-382

Chen S, Wang L, Que ZQ, Pan RQ, Pan QH (2005) Genetic and physical mapping of $P i 37(t)$, a new gene conferring resistance to rice blast in the famous cultivar St. No. 1. Theor. Appl. Genet. 111:1563-1570

Couch BC, Kohn LM (2002) A multilocus gene genealogy concordant with host preference indicates segregation of a new species, Magnaporthe oryzae, from M. grisea. Mycologia 94: 683-693
Chen X, Temnykh S, Xu Y, Cho YG, McCouch SR (1997) Development of a microsatellite framework map providing genomewide coverage in rice (Oryza sativa L.). Theor. Appl. Genet. 95:553-567

Ghulam M, Muhammad MA, Sami UK, Muhammad N, Abdul SM (2013) Leaf rust resistance in semi dwarf wheat cultivars: a conspectus of post green revolution period in pakistan. Pakistan Journal of Botany 45:415-422

Han SS, Ryu JD, Shim HS, Lee SW, Hong YK, Cha KH (2001) Breakdown of resistant cultivars by new race $\mathrm{KI}-1117 \mathrm{a}$ and race distribution of rice blast fungus during 1999-2000 in Korea. Res. Plant Dis. 7:86-92 (in Korean)

Hibino H (1983) Relations of rice tungro bacilliform and spherical viruses with their vector Nephotettix virescens Annals of the Phytopathological Society of Japan 49:545-553

Hittalmani S, Parco A, Mew T, Zeigler R, Huang N (2000) Fine mapping and DNA marker-assisted pyramiding of the three major genes for blast resistance in rice. Theor. Appl. Genet.100: $1121-1128$

Huang N, Angeles ER, Domingo J, Magpantay G, Singh S, Zhang G, Kumaravadivel N, Bennett J, Khush GS (1997) Pyramiding of bacterial blight resistance genes in rice: marker assisted selection using RFLP and PCR. Theor Appl Genet 95:313-320

Hur YJ, Jeung JU, Kim SY, Park HS, Cho JH, Lee JY et al. (2013) Functional markers for bacterial blight resistance gene $\mathrm{Xa} 3$ in rice. Mol. Breed. 31:981-985

Jiang Y, Cai Z, Xie W, Long T, Yu H, Zhang Q(2012) Rice functional genomics research: Progress and implications for crop genetic improvement. Biotechnology Advances 30:1059-1070 http:// dx.doi.org/10.1016/j.biotechadv.2011.08.013

Jena KK, Jeung JU, Lee JH, Choi HC, Brar DS (2006) High resolution mapping of a new brown planthopper (BPH) resistance gene, $B p h 18(t)$, and marker-assisted selection for BPH resistance in rice (Oryza sativa L.). Theor. Appl. Genet. 112:288-297

Jia Y, Wang Z, Singh P (2002) Development of dominant rice blast Pi-ta resistance gene markers. Crop Sci. 42:2145-2149

Jia Y, Redus M, Wang Z, Rutger JN (2004) Development of a SNLP marker from the Pi-ta blast resistance gene by tri-primer PCR. Euphytica 138:97-105

Joseph M, Gopalakrishnan S, Sharma RK, Singh VP, Singh AK, Singh NK, Mohapatra T (2004) Combining bacterial blight resistance and basmati quality characteristics by phenotypic and molecular marker-assisted selection in rice. Mol Breed. 13: 377-387

Kim SM, Sohn JK (2005) Identification of a Rice Gene (Bph 1) Conferring Resistance to Brown Planthopper (Nilaparvata lugens Stal) Using STS Markers. Mol. Cells. 20(1):30-34

Kinoshita T (1995) Report of committee on gene symbolization, nomenclature and linkage groups. Rice Genet Newsl 12:9-153

Koide, Y, Kobayashi N, Xu D, Fukuta Y (2009) Resistance genes and selection DNA markers for blast disease in rice (Oryza sativa L.). JARQ. 43(4):255-280

Koressaar T, Remm M (2007) Enhancements and modifications of primer design program Primer3 Bioinformatics 23(10):1289-91 
Kump B, Javornik B (1996) Evaluation of genetic variability among common buckwheat (Fagopyrum esculentum Moench) populations by RAPD markers. Plant Science 114:149-158

Kwon SW, Cho YC, Kim YG, Suh JP, Jeung JU, Roh JH, et al. (2008) Development of Near-isogenic Japonica rice lines with enhanced resistance to Magnaporthe grisea. Mol. Cells 25:407-416

Lammerts van Bueren ET, Backes G, de Vriend H, Ostergard H (2010) The role of molecular markers and marker assisted selection in breeding for organic agriculture. Euphytica 175:51-64

Lee JH, Muhsin M, Atienza GA, Kwak DY, Kim SM, Leon TB, et al. (2010) Single nucleotide polymorphisms in a gene for translation initiation factor (eIF4G) of rice (Oryza sativa) associated with resistance to Rice tungro spherical virus. Mol. Plant Microbe Interact 23:29-38

Luck J, Spackman M, Freeman A, Trebicki P, Griffiths W, Finlay K, Chakraborty S (2011) Climate change and diseases of food crops. Plant Pathology 60:113-121

Maclean JL, Dawe DC, Hardy B, Hettel GP (2002) Rice almanac (Third Edition). Philippines, IRRI, WARDA, CIAT and FAO

Madgwick JW, West JS, White RP, Semenov MA, Townsend JA, Turner JA, Fitt BDL (2011) Impacts of climate change on wheat anthesis and fusarium ear blight in the UK. European Journal of Plant Pathology 130:117-131

Niño M, Lee HJ, Kim J, Abdulal S, Jung YJ, Kang KK, Nou I, Cho YG(2015) Enhancement of Rice Resistance to Bacterial Blight by Overexpressing $\mathrm{BrCP} 3$ Gene of Brassica rapa. Plant Breed. Biotech. 3(4):355-365

McCouch SR, Teytelman L, Xu YB, Lobos KB, Clare K, Walton M, et al. (2002) Development and mapping of 2,240 new SSR markers for rice (Oryza sativa L.). DNA Res 9:199-207

Mew TW (1987) Current status and future prospects of research on bacterial blight of rice. Annu. Rev. Phytopathol. 25:359-382

Nogoy FM, Song JY, Ouk S, Rahimi S, Kwon SW, Kang KK, Cho YG (2016) Current Applicable DNA Markers for Marker Assisted Breeding in Abiotic and Biotic Stress Tolerance in Rice (Oryza sativa L.) Plant Breed. Biotech. 4(3):271-284

Porter BW, Chittoor JM, Yano M, Sasaki T, et al. (2003) Development and mapping of markers linked to the rice bacterial blight resistance gene Xa7. Crop Sci. 43: 1484-1492

Porter JR, Semenov MA (2005) Crop responses to climatic variation. Philosophical Transactions of the Royal Society B: Biological Sciences 360:2021-2035

Pradhan SK, Nayak DK, Mohanty S, Behera L, Barik SR, Pandit E, et al. (2015) Pyramiding of three bacterial blight resistance genes for broad-spectrum resistance in deepwater rice variety, Jalmagna. Rice 8:19

Rajpurohit D, Kumar R, Kumar M, Paul P, Awasthi AA, et al. (2011) Pyramiding of two bacterial blight resistance and a semi dwarfing gene in Type 3 Basmati using marker-assisted selection. Euphytica 178:111-126
Ramkumar G, Madhav MS, Rama Devi SJS, Prasad MS, Ravindra Babu V (2015) Nucleotide variation and identification of novel blast resistance alleles of Pib by allele mining strategy. Physiol Mol Biol Plants. 21(2):301-304

Sasaki T, Burr B (2000) International Rice Genome Sequencing Project: The effort to completely sequence the rice genome. Curr. Opin. Plant Biol. 3:138-141

Singh AK, Singh PK, Arya M, Singh NK, Singh US (2015) Molecular screening of blast resistance genes in rice using SSR markers. Plant Pathol. J. 31:12-24

Singh AK, Gopala Krishnan S, Singh VP, Prabhu KV, Mohapatra T, Singh NK, et al. (2011) Marker assisted selection: a paradigm shift in Basmati breeding. Indian Journal of Genetics and Plant Breeding 71:1-9

Song JY, Lee GA, Choi YM, Lee S, Lee KB, Bae CH, et al. (2014) Blast resistant genes distribution and resistance reaction to blast in Korean landraces of rice (Oryza sativa L.). Korean J. Plant Res. 27(6):687-700

Sun L, Su C, Wang C, Zai H, Wan J (2005) Mapping of a major resistance gene to brown planthopper in the rice cultivar Rathu Heenati. Breed. Sci. 55:391-396

Talbot NJ, Foster AJ (2001) Genetics and genomics of the rice blast fungus Magnaporthe grisea: developing an experimental model for understanding fungal diseases of cereals. Adv. Bot. Res. 34: 263-287

Talbot NJ (2003) On the trail of a cereal killer: investigating the biology of Magnaporthe grisea. Annu. Rev. Microbiol. 57: 177-202

Untergasser A, Cutcutache I, Koressaar T, Ye J, Faircloth BC, Remm M, Rozen SG (2012) Primer3 - new capabilities and interfaces. Nucleic Acids Research 40(15):e115

Wang Q, Lu C, Zhang Q (2005) Midday photoinhibition of two newly developed super-rice hybrids. Photosynthetica 43:277-281

Wang ZX, Yano M, Yamanouchi U, Iwamoto M, Monna L, Hayasaka H, Katayose Y, Sasaki T (1999) The Pib gene for rice blast resistance belongs to the nucleotide binding and leucinerich repeat class of plant disease resistance genes. Plant J. 19: 55-64

Yaegashi H (1994) Use of resistant varieties and disease control for paddy rice. Agric. Hortic. 69:149-154

Yamasaki M, Yoshimura A, Yasui H(2003) Genetic basis of ovicidal response to whitebacked planthopper (Sogatella furcifera Horvath) in rice (Oryza sativa L.). Molecular Breeding 12(2):133-143

Zeigler RS, Thome J, Nelson J, Levy M, Correa-Victoria FJ (1994) Lineage exclusion: A proposal for linking blast population analysis to resistance breeding: In Zeigler R.S., S.A Leong and P. Teng (eds.), Rice Blast Disease, CAB International, Wallingford, UK. pp 267-292

Zhang G, Angeles ER, Abenes MLP, Khush GS, et al. (1996) RAPD and RFLP mapping of the bacterial blight resistance gene $\mathrm{Xa}-13$ in rice. Theor. Appl. Genet. 93:65-70 